NASA Technical Memorandum 4792

\title{
Overview of Recent Flight Flutter Testing Research at NASA Dryden
}

Martin J. Brenner, Richard C. Lind, and David F. Voracek

Dryden Flight Research Center

Edwards, California

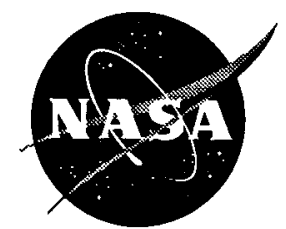

National Aeronautics and

Space Administration

Office of Management

Scientific and Technical Information Program 



\title{
OVERVIEW OF RECENT FLIGHT FLUTTER TESTING RESEARCH AT NASA DRYDEN
}

\author{
Martin J. Brenner, ${ }^{*}$ Richard C. Lind, ${ }^{\dagger}$ David F. Voracek ${ }^{\ddagger}$ \\ NASA Dryden Flight Research Center \\ Edwards, California
}

\begin{abstract}
$\underline{\text { Abstract }}$
In response to the concerns of the aeroelastic community, NASA Dryden Flight Research Center, Edwards, California, is conducting research into improving the flight flutter (including aeroservoelasticity) test process with more accurate and automated techniques for stability boundary prediction. The important elements of this effort so far include the following: 1) excitation mechanisms for enhanced vibration data to reduce uncertainty levels in stability estimates; 2) investigation of a variety of frequency, time, and wavelet analysis techniques for signal processing, stability estimation, and nonlinear identification; and 3) robust flutter boundary prediction to substantially reduce the test matrix for flutter clearance. These are critical research topics addressing the concerns of a recent AGARD Specialists' Meeting on Advanced Aeroservoelastic Testing and Data Analysis. This paper addresses these items using flight test data from the F/A-18 Systems Research Aircraft and the F/A-18 High Alpha Research Vehicle.

\section{$\underline{\text { Nomenclature }}$}

a wavelet scaling parameter

AGARD Advisory Group for Aerospace Research and Development

AOA angle of attack
\end{abstract}

\footnotetext{
* Research Engineer, NASA, Dryden Flight Research Center, MS 4840D/RS, Edwards, CA 93523-0273, 805.258.3793, gonzo@xrd. dfrc.nasa.gov.

${ }^{\dagger}$ NRC Post Doctoral Research Fellow, NASA, Dryden Flight Research Center, MS 4840D/RS, Edwards, CA 93523-0273, 805. 258.3075, lind@xrd.dfrc.nasa.gov, Member AIAA.

$\ddagger$ Research Engineer, NASA, Dryden Flight Research Center, MS 4840D/RS, Edwards, CA 93523-0273, 805.258.2463, voracek@flutter. dfrc.nasa.gov. Senior Member AIAA.

Copyright $(\mathcal{C} 1997$ by the American Institute of Aeronautics and Astronautics, Inc. No copyright is asserted in the United States under Title 17, U.S. Code. The U.S. Government has a royalty-free license to exercise all rights under the copyright claimed herein for Governmental purposes. All other rights are reserved by the copyright owner.
}

AR autoregressive

ASE aeroservoelastic

CWT continuous wavelet coefficient

ERA eigensystem realization algorithm

FFT fast Fourier transform

FORSE Frequency domain Observability Range Space Extraction

$G \quad$ spectral estimate

$h(t) \quad$ wavelet basis function

$H_{1}, H_{2}, H_{v}$ transfer function estimates

HARV High Alpha Research Vehicle

$H_{\infty}$ norm supremum norm over finite magnitude transfer functions

ID identification

IV instrumental variable estimation

$k \quad$ summation index

$l_{1}$ norm induced norm over signals of finite magnitude

$l_{2}$ norm norm of signals that are square integrable

$l_{\infty}$ norm induced norm over signals of finite magnitude impulse response

LS least squares

Mach, $\bar{q} \quad$ critical flight parameters

MEM maximum entropy method

MIMO multi-input-multi-output

MLE maximum likelihood estimation

N4SID numerical algorithms for subspace statespace system identification

OBES on-board excitation system

OKID Observer/Kalman filter identification 


\begin{tabular}{|c|c|}
\hline ORSE & Observability Range Space Extraction \\
\hline PEM & prediction error method \\
\hline$p k$ & $\begin{array}{l}\text { computational method for unsteady } \\
\text { aerodynamics }\end{array}$ \\
\hline PSD & power spectral density \\
\hline psf & pounds per square foot \\
\hline $\bar{q}$ & dynamic pressure \\
\hline SISO & single-input-single-output \\
\hline sps & samples per second \\
\hline SRA & Systems Research Aircraft \\
\hline$t$ & time \\
\hline$T$ & transform of $x(t)$ \\
\hline TVCS & thrust vectoring control system \\
\hline$W_{\text {in }}$ & input uncertainty weighting \\
\hline$x(t)$ & time domain data \\
\hline$X(t, \omega)$ & time-frequency domain data \\
\hline
\end{tabular}

Subscripts

$x, y \quad$ input and output data for spectral estimates

Symbols

$\delta_{\bar{q}} \quad$ parametric variation of dynamic pressure

$\Delta_{i n} \quad$ input multiplicative uncertainty

$\Delta_{\text {modes }} \quad$ real parametric modal uncertainty

$\mu \quad$ structured singular value

$\tau \quad$ wavelet time shift parameter

$\omega \quad$ radian frequency

* $\quad$ complex conjugate transpose

$\sum \quad$ summation

\section{Introduction}

Flight flutter testing continues to be a challenging research area because of the concerns with cost, time, and safety in expanding the envelope of new or modified aircraft. Testing is often done at stabilized test points to generate numerous data sets while attempting to estimate aeroelastic stability in an accurate and efficient manner. Parameter estimation methods generally produce inconsistent results because of poor excitation, closely spaced modes, noisy data, nonlinearities, and low modal stability levels. Flutter test procedures are desired which will dramatically reduce test time, increase reliability, and provide accurate and conservative results.

In response to the concerns of the aeroelastic community and in-house requirements, NASA Dryden Flight Research Center, Edwards, California, is conducting research into improving the flight flutter test process (including aeroservoelasticity) with more accurate and automated techniques for stability boundary prediction. The important elements of this effort so far include the following research:

1. Excitation mechanisms are being studied for enhanced vibration data to reduce uncertainty levels in stability estimates. A wingtip aerodynamic excitation system was used for improved aeroelastic excitation, and signals generated from a flight control system were programmed to activate the control surfaces for aeroservoelastic excitation.

2. A variety of frequency, time, and wavelet analysis techniques are being investigated for signal processing, stability estimation, and system identification. Traditional Fourier methods for frequency response are being augmented with autoregressive estimation methods. Numerous algorithms to estimate stability parameters and system dynamic models are being compared for efficiency and reliability. Time-frequency signal processing techniques are used for filtering, system identification, and detection of nonlinearities.

3. Robust flutter boundary prediction methods are being developed to substantially reduce the test matrix for flutter clearance. These methods rely on identification consistent with the uncertainty structure in an aeroelastic model, thereby providing an explicit measure of stability for robust model validation. Accounting for the uncertainty structure in this manner guarantees that any system will remain stable within a confidence bound.

These are critical research topics addressing the concerns of a recent AGARD Specialists' Meeting on Advanced Aeroservoelastic Testing and Data Analysis. This paper addresses these items using a wingtip aerodynamic structural excitation system on the F/A-18 Systems Research Aircraft (SRA) and an oscillating control surface excitation system on the F/A-18 High Alpha Research Vehicle (HARV).

A flight flutter research program was initiated on the F/A-18 SRA in late 1994. The purpose of the SRA 
structural dynamics research to date was to accomplish the following:

- Study the integrity and effectiveness of the excitation system in a wide variety of subsonic, transonic, and supersonic test conditions.

- Investigate data properties over a range of linear and logarithmic sinusoidal inputs at different force levels in a flight flutter test environment. Compare analysis algorithms in the frequency, time, and wavelet domains using the time-varying data sets.

- Identify nonlinear behavior, such as that resulting from transonic dynamics.

- Create a comprehensive data base of transient flight flutter data for the aeroelasticity and system identification disciplines to support development of advanced flight flutter test and analysis methods.

This paper presents F/A-18 SRA flight test results and analyses using the wingtip exciter. Preliminary results from the F/A-18 HARV aircraft using an on-board excitation system (OBES) for control surface excitation are also presented. Flight flutter test technique research was conducted on the F/A-18 HARV to study the effectiveness of Schroeder-pulsed and sincpulse waveforms as excitation signals. Present modal estimation methods are reviewed, followed by an outline of the robust aeroelastic model development, with the ultimate objective being model validation for robust flutter boundary prediction. A novel procedure for computing the robust flutter boundary from flightderived uncertainty models, using the structured singular value $(\mu)$, is introduced.

\section{Aircraft Descriptions of the F/A-18 SRA and HARV}

The F/A-18 SRA aircraft is being flight tested at the NASA Dryden Flight Research Center primarily for flight systems experiments such as optical sensing, new actuation concepts, smart structures, and advanced airdata and flight control systems. Generally, it is very much like a standard production F/A-18. A major left wing structural modification was done, however, on the SRA aircraft to allow for testing of several hydraulic and electromechanical advanced aileron actuator concepts. Because the test actuators may be larger than the standard one, a fitting called a 'hinge-half' supporting the aileron hinge, the actuator, and a fairing had to be replaced by larger and heavier items. A total of about $35 \mathrm{lb}$ was added to the wing. Table 1 lists calculated modal frequencies for symmetric and antisymmetric modes for the F/A-18 SRA aircraft with left wing modifications.

Another F/A-18 aircraft (fig. 1) was modified at NASA Dryden to perform flight research at high angle-of-attack (AOA) using thrust vectoring and incorporating control law concepts for agility and

Table 1. F/A-18 SRA with left wing modifications and without wingtip exciter: calculated elastic modal frequencies. Fuel loading is FULL.

\begin{tabular}{lcll}
\hline \hline Symmetric mode & $\mathrm{Hz}$ & Antisymmetric mode & $\mathrm{Hz}$ \\
\hline Wing first bending & 5.59 & Fuselage first bending & 8.15 \\
Fuselage first bending & 9.30 & Wing first bending & 8.84 \\
Stabilator first bending & 13.21 & Stabilator first bending & 12.98 \\
Wing first torsion & 13.98 & Wing first torsion & 14.85 \\
Vertical tail first bending & 16.83 & Vertical Tail first bending & 15.61 \\
Wing second bending & 16.95 & Wing second bending & 16.79 \\
Wing outboard torsion & 17.22 & Fuselage second bending & 18.62 \\
Fuselage second bending & 19.81 & Trailing edge flap rotation & 23.47 \\
Trailing edge flap rotation & 23.70 & Fuselage torsion & 24.19 \\
Stabilator fore and aft & 28.31 & Launcher rail lateral & 24.35 \\
Wing second torsion & 29.88 & Stabilator fore and aft & 28.58 \\
Fuselage third bend, aileron rotation & 33.44 & Wing second torsion & 29.93 \\
Aileron torsion & 38.60 & Aft fuselage torsion & 37.80 \\
Stabilator second bending, wing & 43.17 & Wing pitch & 39.18 \\
$\quad$ third bending & & & \\
\hline \hline
\end{tabular}




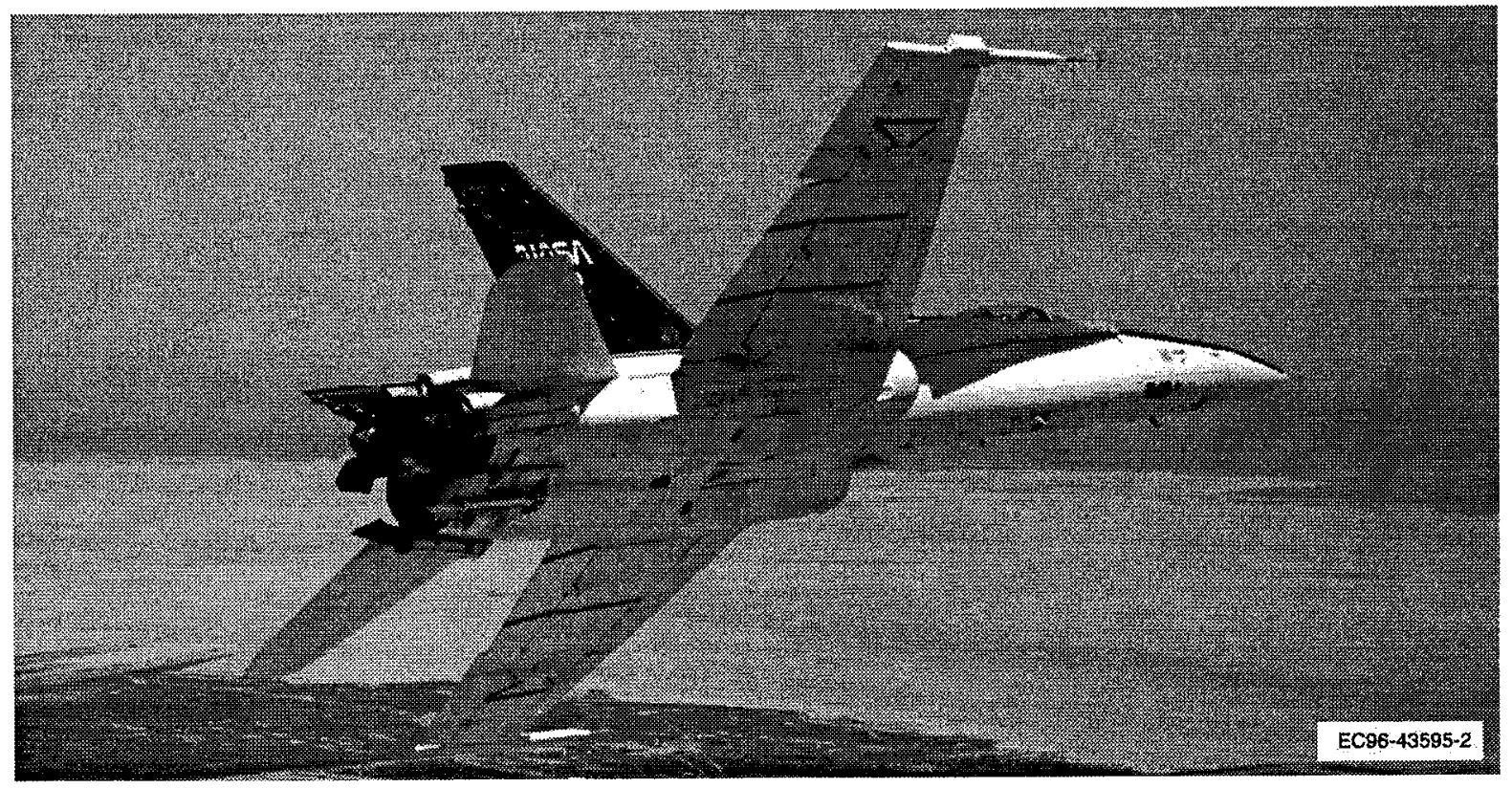

Figure 1. F/A-18 HARV.

performance enhancement, as well as providing data for correlation with computational fluid dynamics solutions. This vehicle is called the High-Alpha Research Vehicle with Thrust Vectoring Control System (HARV-TVCS), referred to simply as the HARV throughout this report. As opposed to the SRA, the HARV was structurally very different from a standard F/A-18 aircraft, as can be seen by comparing the HARV modal data in table 2 with the SRA data in table 1.
Modifications include addition of Inconel ${ }^{\circledR}$ vanes in each engine exhaust for thrust vectoring and corresponding ballast in the forward fuselage to maintain the aircraft center-of-gravity location. Also added were a research flight control system for feedback control of aerodynamic surfaces and the vanes, an inertial navigation system for AOA and sideslip rate feedbacks, wingtip AOA vanes and pressure probes (for airdata research purposes), and additional

Table 2. F/A-18 HARV-TVCS calculated elastic modal frequencies. Fuel loading is FULL.

\begin{tabular}{lrlr}
\hline \hline Symmetric mode & $\mathrm{Hz}$ & Antisymmetric mode & $\mathrm{Hz}$ \\
\hline Wing first bending & 5.72 & Fuselage first bending & 6.81 \\
Fuselage first bending & 7.45 & Wing first bending & 8.91 \\
Wing first torsion & 11.64 & Wing first torsion & 11.91 \\
Stabilator first bending & 13.68 & Stabilator first bending & 13.65 \\
Wing fore-aft & 18.10 & Wing fore-aft & 15.07 \\
Vertical tail first bending & 15.93 & Vertical tail first bending & 15.63 \\
Wing second bending & 17.04 & Fuselage first torsion & 18.82 \\
Fuselage second bending & 15.32 & Fuselage second bending & 21.03 \\
Exhaust vane rotation & 22.10 & Exhaust vane rotation & 22.10 \\
Inboard flap rotation & 23.47 & Inboard flap rotation & 23.03 \\
Stabilator fore-aft & 27.33 & Fore-fuselage torsion & 23.97 \\
\hline \hline
\end{tabular}

\footnotetext{
${ }^{\circledR}$ Inconel is a registered trademark of Huntington Alloy Products Div., International Nickel Co., Huntington, West Virigina.
} 
instrumentation for loads, vane temperatures, and structural dynamics. ${ }^{1}$

\section{Excitation Systems}

This section describes the excitation systems used for aeroelastic response on the SRA and aeroservoelastic excitation of the F/A-18 HARV aircraft. System descriptions, test procedures, flight experience, and test results are discussed for each aircraft.

\section{Wingtip Aeroelastic Excitation}

Aeroelastic excitation of the F/A-18 SRA is discussed in this section. Details of the system and flight testing experience is supplemented with flight test results.

\section{System Description}

The structural modifications to the SRA prompted a flight flutter envelope expansion and follow-on extensive aeroelastic excitation research program with a dual wingtip structural excitation system. Figure 2 shows this wingtip excitation system is a modification of the single wingtip version used on an F-16XL. ${ }^{2}$ Exciters were $15 \mathrm{lb}$ mounted on each wingtip. The difference in modal frequencies with exciters and without exciters (table 1) averaged $0.15 \mathrm{~Hz}$ with a maximum of $0.72 \mathrm{~Hz}$. Each exciter has a small fixed aerodynamic vane forward of a rotating slotted hollow cylinder (fig. 2). When the cylinder rotates, the aerodynamic pressure distribution on the vane generates a force changing at twice the cylinder rotation frequency. The vane is controlled from a cockpit control box which activates an avionics box mounted in the instrumentation bay. The avionics box powers a variable-speed motor in the vane exciter assembly. Two force levels are possible by adjusting the slot openings to 25 percent (low-force, inner cylinder closed) or 75 percent (high-force, inner cylinder open). Three possible positions for the exciters were midwingtip, forward wingtip at the wingtip leading edge, and aft wingtip near the wingtip trailing edge (fig. 2).

Other flight programs $s^{3,4,5}$ have used this system with varying degrees of success. In particular, the dual system operates either symmetrically or antisymmetrically by attempting to maintain a constant $\left(0^{\circ}\right.$ or $180^{\circ}$, respectively) phase relationship between exciters. At higher dynamic pressure, the exciters were known to exhibit erratic phase-gain behavior due to binding in both the motor drive mechanism and rotating cylinders. ${ }^{5}$ Testing at Dryden exhibited the same type of characteristics with the exciters on the F/A-18 SRA. Figure 3 shows an example of phase difference between right- and left-wing exciters for both low and high dynamic pressure. At low dynamic pressure, the phase between exciters is relatively constant near zero compared with the high dynamic pressure condition, where the phase varies randomly. Most conditions tested

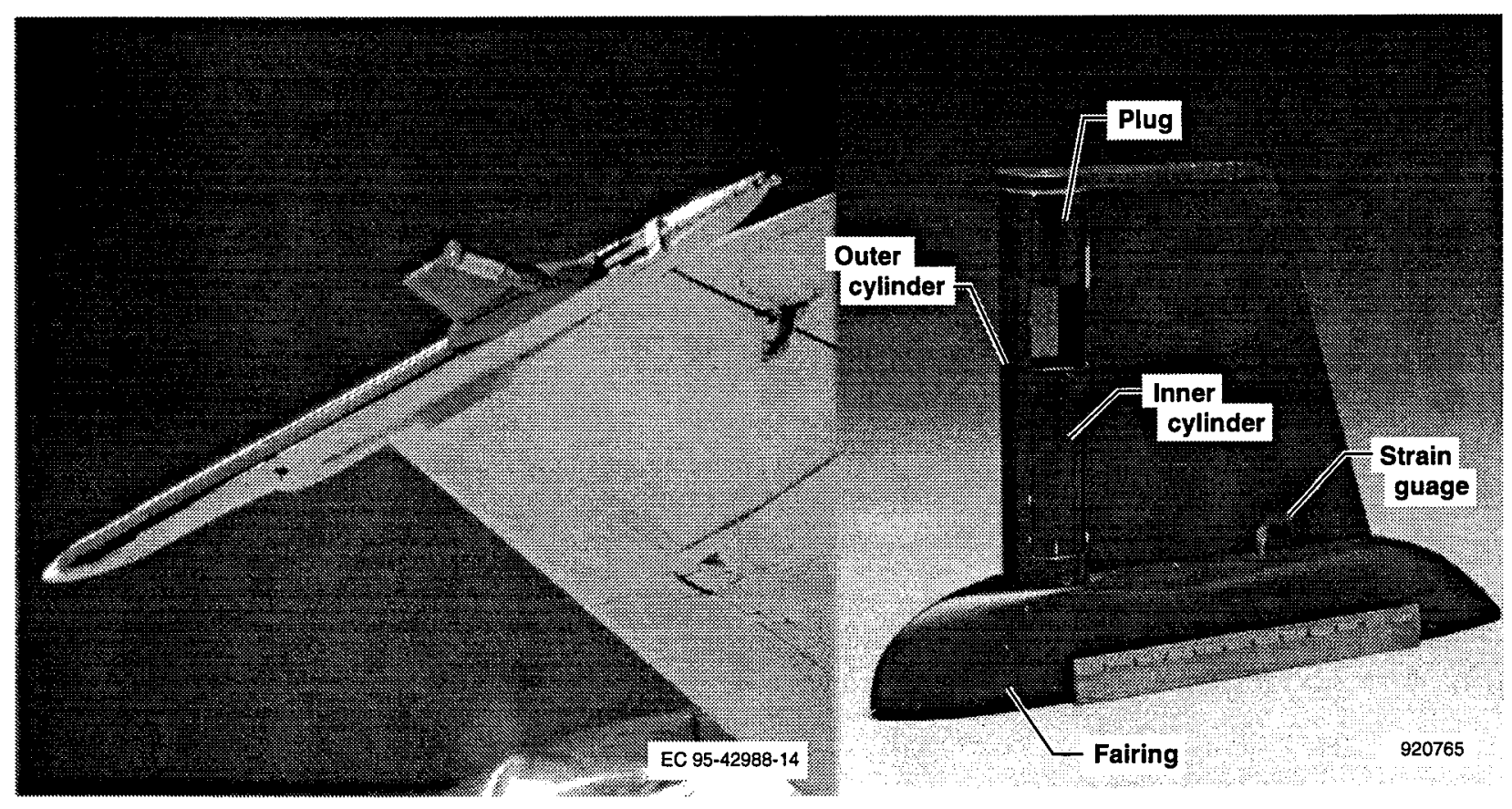

Figure 2. Wingtip exciter for F/A-18 SRA (right) and installed on the aircraft in the aft wingtip position (left). 

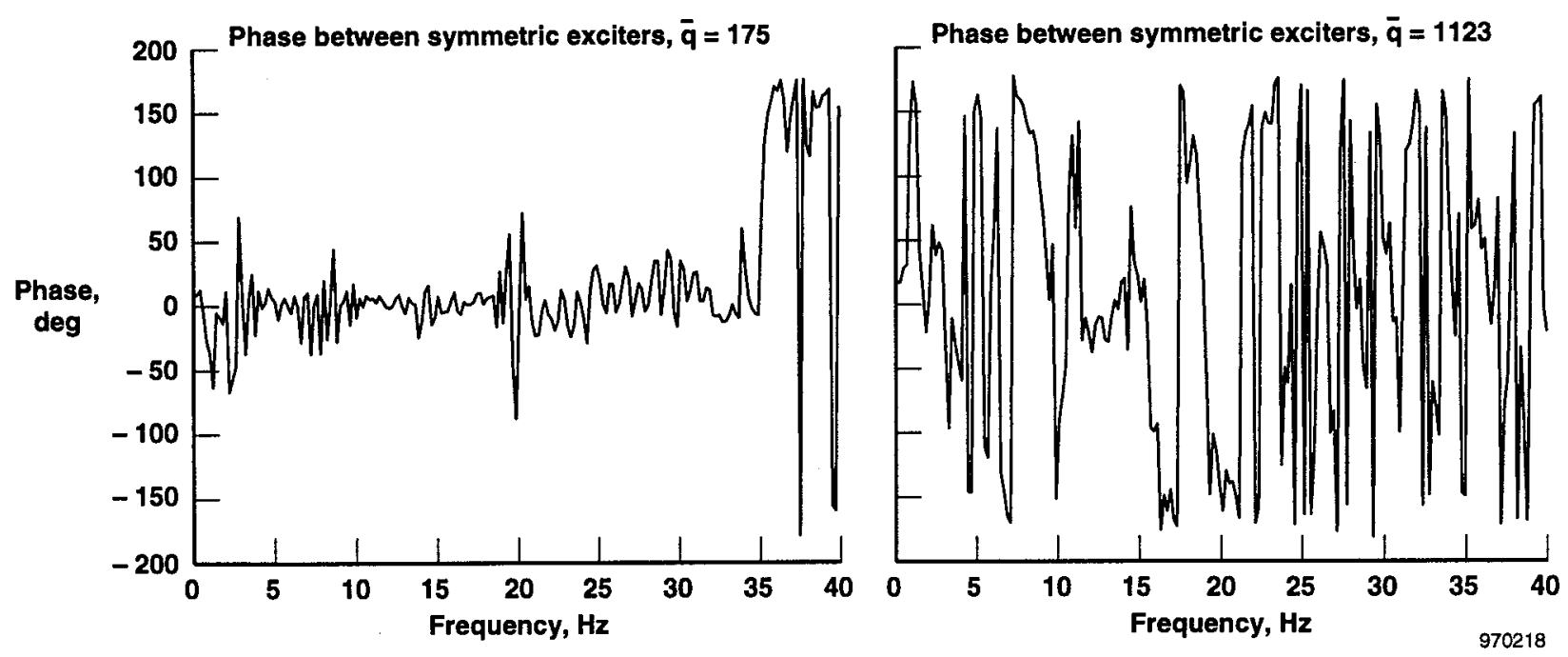

Figure 3. Phase between left and right wingtip exciter force inputs for symmetric excitation. Low dynamic pressure at 175 psf (left). High dynamic pressure at 1123 psf (right).

had some phase discrepancy of the measured force which was caused by both the phase degradation in the individual exciters and to asymmetries in the aeroelastic dynamics of the aircraft. However, the phase discrepancies did not detract from the effectiveness of the structural excitation, and it was still possible to extract the proper transfer functions from each exciter to the individual accelerometer responses. ${ }^{6}$ Furthermore, both symmetric and antisymmetric modes were excited for a particular sweep, whether it was a symmetric or antisymmetric sweep.

\section{Test Procedure}

Linear and logarithmic sinusoidal sweeps up to $40 \mathrm{~Hz}$ were used on the F/A-18 SRA, although the exciter is capable of sweeping to $50 \mathrm{~Hz}$. The exciters were mounted on the wingtip launcher rails in forward and aft position, independently. They were operated in both low-force and high-force modes for 15-, 30-, or 60-sec forward and reverse frequency sweeps. Some sweeps were actually multiples of two or four shorter duration sweeps with no interrupt. Generally sweeps were performed for symmetric and antisymmetric excitation in each configuration. A total of 260 test points were flown with the exciters in one or more of these optional configurations at the specified flight condition. The test parameters are summarized in table 3.

These test points were conducted to determine the excitation system effectiveness in the subsonic, transonic, and supersonic regimes. Frequency ranges were chosen to excite the primary modes used in the aeroelastic analysis, shown in table 1 . A $3-12 \mathrm{~Hz}$ sweep attempted to distinguish the first wing and fuselage bending modes, and the $25-35 \mathrm{~Hz}$ sweep was done to excite the aileron rotation mode for detection of any transonic aileron buzz phenomena. Acceleration measurements were taken at $200 \mathrm{sps}$ from the fore and aft wingtips, ailerons, and vertical and horizontal tails.

Table 3. F/A-18 SRA aeroelastic flight test matrix.

\begin{tabular}{ll}
\hline \hline Exciter configuration & Symmetric, antisymmetric, and independent \\
Exciter position & Both forward, both aft, and left-aft/right-forward \\
Mach & $0.54,0.65,0.70,0.80,0.85,0.90,0.95,1.05,1.2,1.4,1.6$ \\
Altitude, ft & $10 \mathrm{k}, 30 \mathrm{k}$, and 40k \\
Force & Low and high \\
Sweep & Linear and logarithmic \\
Duration, sec & 15,30, and 60 \\
Range, $\mathrm{Hz}$ & $3-12,3-25,25-35,3-35,35-3$, and 3-40 \\
Multiple & Single, double, and quadruple contiguous sweeps per maneuver \\
\hline \hline
\end{tabular}


Strain gage response, also sampled at 200 sps, was taken at the exciter vane root to monitor the force input at the aircraft wingtip. In reality, the force input is distributed about the vane planform, but for simplicity's sake a point force location was chosen to measure static and dynamic force levels of the vane bending with respect to the wingtip. Vane root strain is assumed to be directly proportional to the vane airloads caused by excitation. It is important to note that this is a measurement of vane strain and not normal force, so it also contains inertial effects from the vane itself as well as modal response of the vane from the aircraft aeroelastic dynamics.

For the last two flights the excitation system software was modified to excite each vane independently, one followed by the other, for each maneuver. Furthermore, lower gear ratios were installed to overcome the previously mentioned binding problem at high dynamic pressure. The new gears reduced the frequency bandwidth of the system from 50 to $25 \mathrm{~Hz}$. Therefore, these last maneuvers were $3-25 \mathrm{~Hz}$ sweeps.

\section{Test Results}

Flutter clearance of the F/A-18 SRA was accomplished before structural dynamics research was performed. Unfortunately, the excitation system had some problems early in the flight clearance phase. Ground operation of the system before flight was satisfactory, but in flight some of the following anomalies occurred:
- Inconsistent rough starts and sweep motion in highforce mode

- Vane cylinders would not open in high-force mode

- Vane cylinders would not reset, or "home," properly after sweep in either high- or low-force mode

These were thought to be environmentally related to ambient temperature, dynamic pressure, or both. Failures were duplicated in ground environmental test chambers at low temperatures, but difficult to reproduce. Some minor modifications in the vane electronics and homing sensors resolved the homing problems, but the problems related to the high-force mode persisted in flight. Subsequently, after eighty maneuvers in six flights it was decided to test only in the low-force mode. This was adequate for envelope clearance and tolerated for research flights.

Spectral information provided the most immediate indication of the quality of data in terms of exciter sweep parameters such as sweep direction, linear as compared with logarithmic and, high- as compared with low-force levels. Variations resulting from these test procedures are important in modal estimation and flutter boundary prediction. For example, to estimate uncertainty sets for robust flutter prediction, numerous data sets are analyzed at the same flight condition to discriminate between dynamic and real model uncertainty, and differences due to test procedure and nonrepeatability. ${ }^{7}$ Figures 4 and 5 show differences that can occur in responses due only to

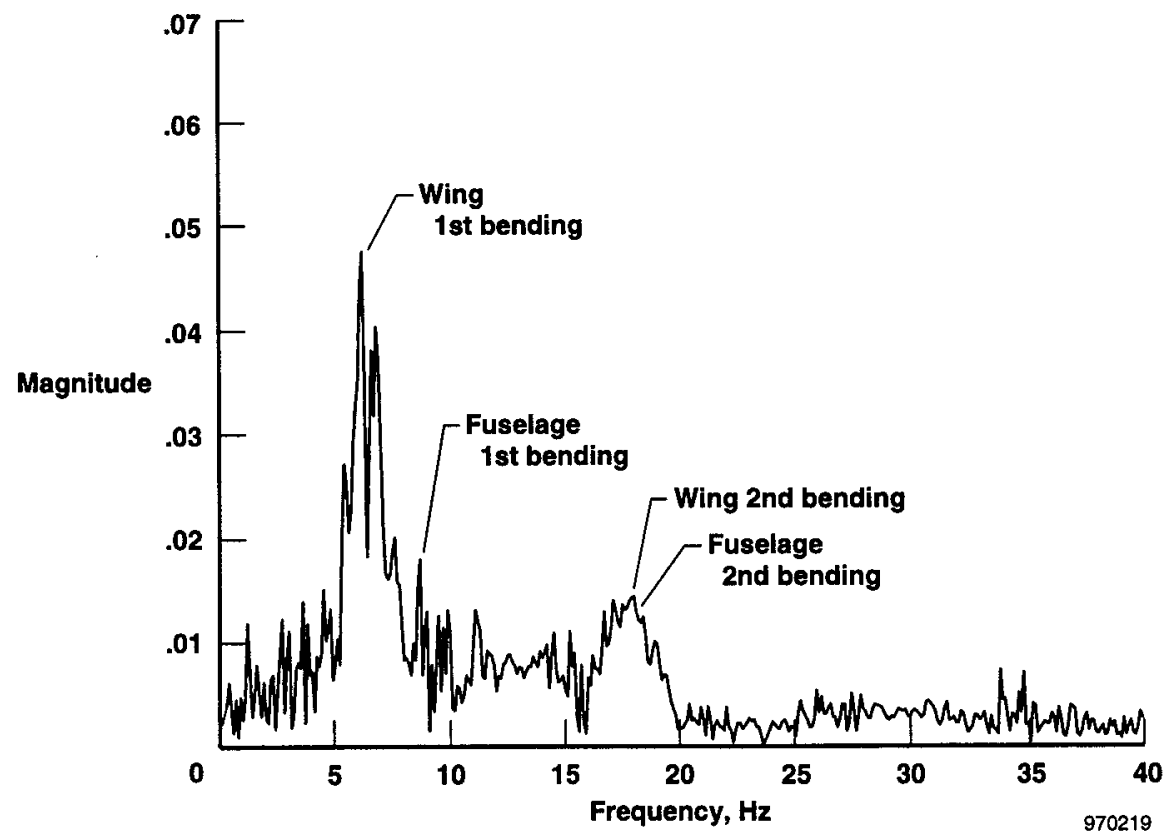

Figure 4. Transfer function of symmetric exciter force to wingtip accelerometer for 30 -sec linearly increasing frequency sweep at $\mathrm{M}=0.8$ and $30 \mathrm{k} \mathrm{ft}$. Sweep range: $3-35 \mathrm{~Hz}$. 


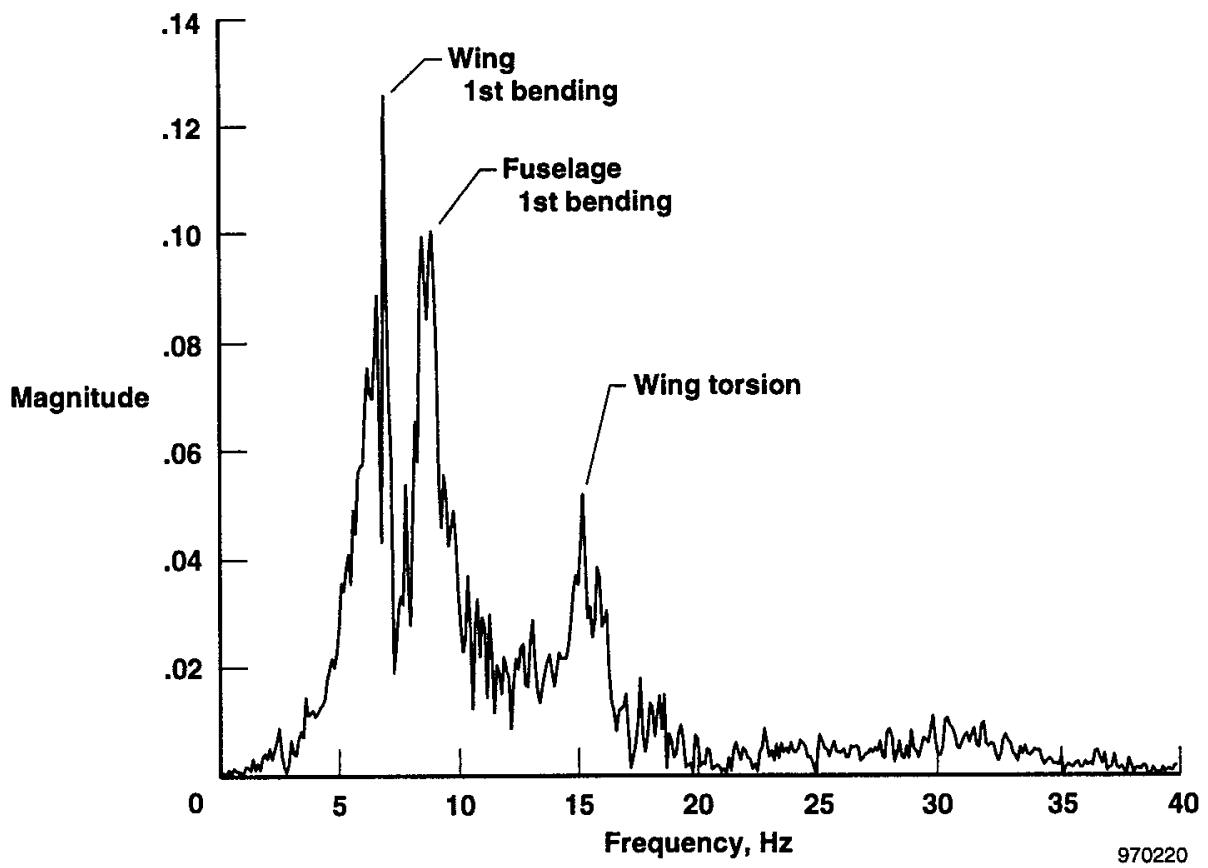

Figure 5. Transfer function of symmetric exciter force to wingtip accelerometer for 30-sec linearly decreasing frequency sweep at $\mathrm{M}=0.8$ and $30 \mathrm{k} \mathrm{ft}$. Sweep range: $35-3 \mathrm{~Hz}$.

the direction of the sweep. Clearly, the decreasing sweep (fig. 5) generally provides much more response, but the increasing sweep (fig. 4) improves modal excitation between $15-20 \mathrm{~Hz}$ relative to the other modes.

The responses in the following PSDs (power spectral densities) were generated at Mach 0.9 , an altitude of $30,000 \mathrm{ft}$, and dynamic pressure of $360 \mathrm{psf}$ from a wingtip accelerometer. With the vanes in the aft wingtip position, an antisymmetric reverse linear $30-\mathrm{sec}$ frequency sweep is compared with a reverse logarithmic sweep in the PSDs of figure 6. Logarithmic sweeps impart more energy in the lower frequencies, illustrated by the first wing bending modes having more power near $6 \mathrm{~Hz}$ and $8 \mathrm{~Hz}$. Figure 7 indicates that there is no significant advantage in increasing the sweep duration from 30 -sec to $60-\mathrm{sec}$. However, figure 8 shows possible improvement in response power by adding more sweeps within the same period of time $(30 \mathrm{sec})$. Antisymmetric wing first bending is much more responsive while the other modes are relatively unaffected by the sweep type. The exception is the significant decrease in modal
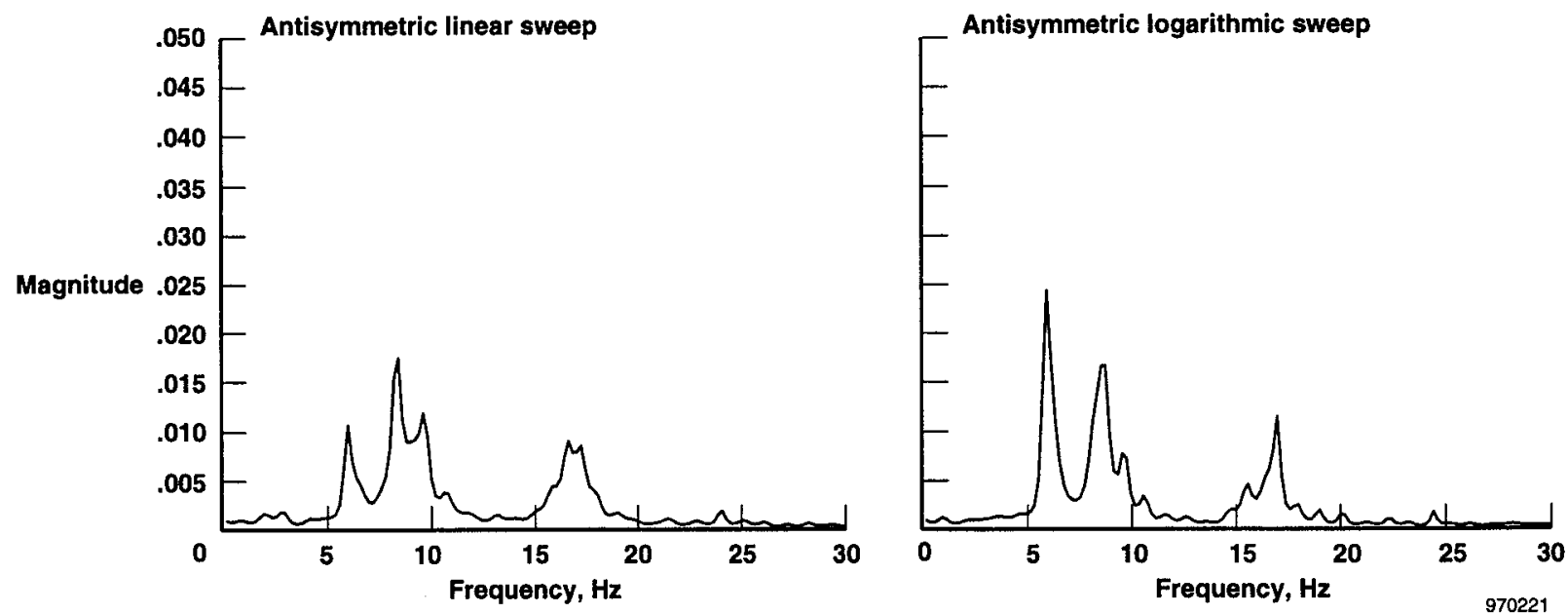

Figure 6. Wingtip accelerometer PSD from antisymmetric linear (left) and logarithmic (right) exciter sweeps. Sweep range: $3-35 \mathrm{~Hz}$. 

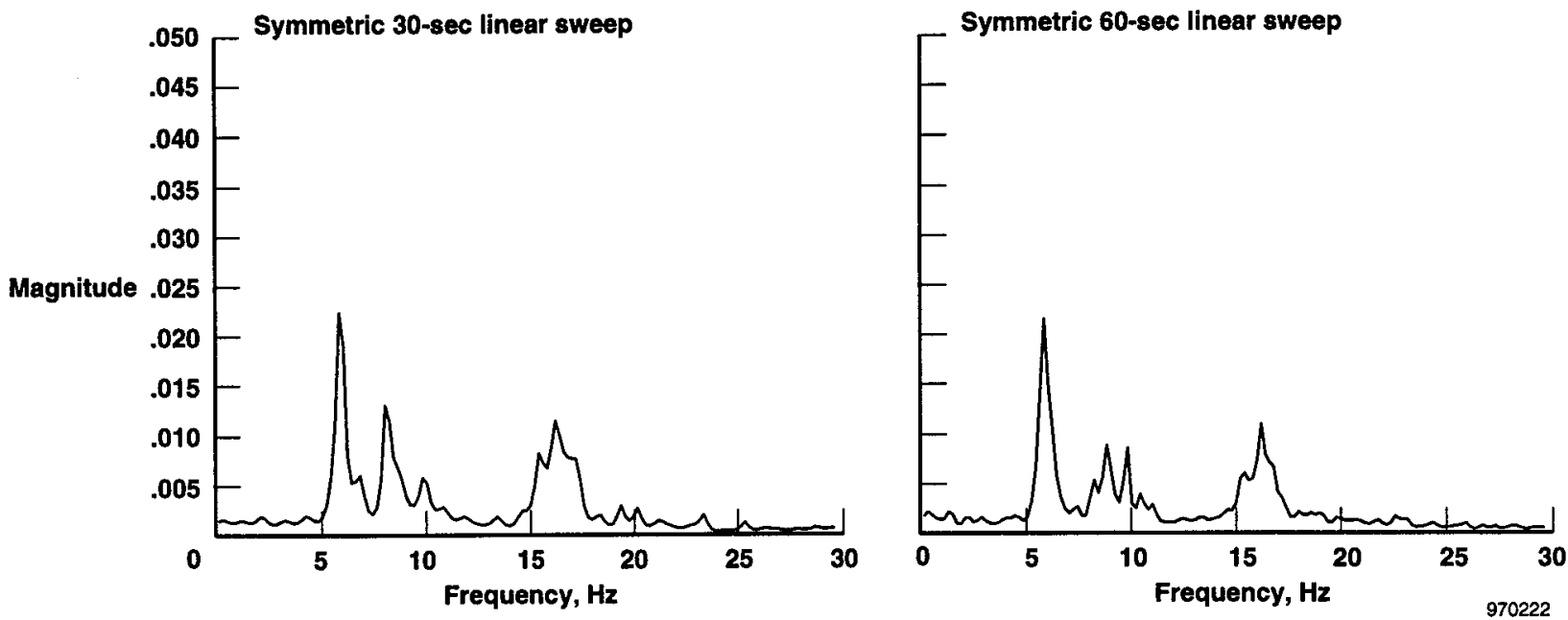

Figure 7. Wingtip accelerometer PSD from symmetric 30-sec (left) and 60-sec (right) exciter sweeps. Sweep range: $3-35 \mathrm{~Hz}$.
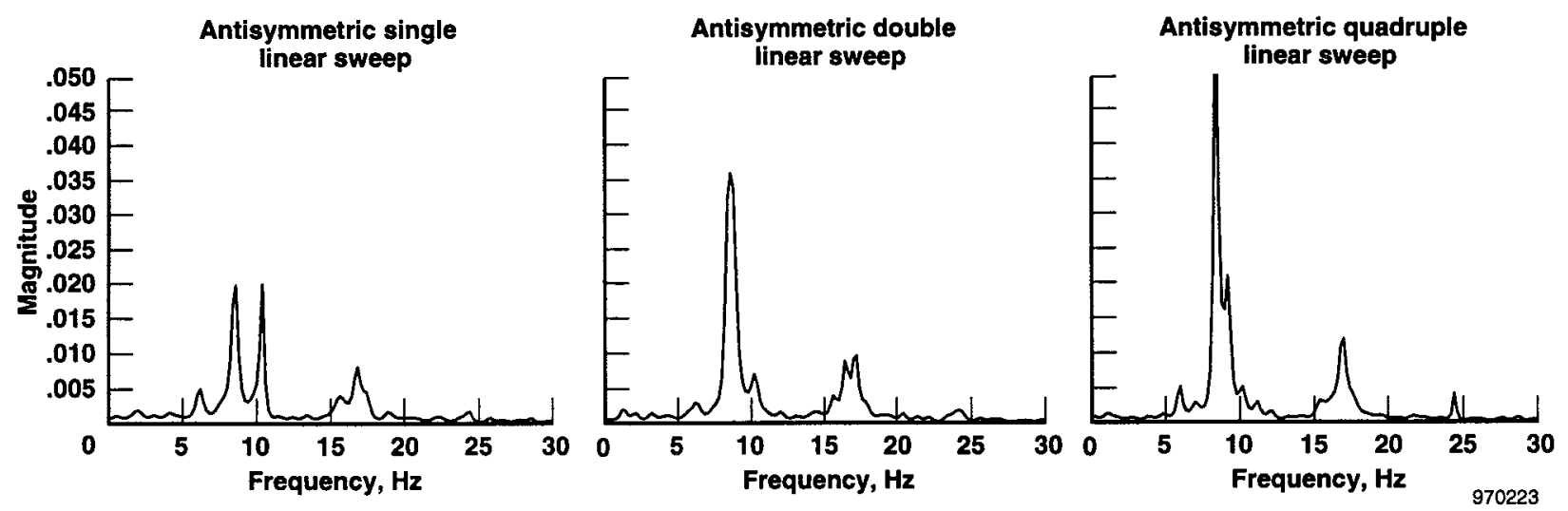

Figure 8. Wingtip accelerometer PSD from antisymmetric single (left), double (middle), and quadruple (right) linear exciter sweeps. Sweep range: $3-35 \mathrm{~Hz}$. Sweep duration: $30-\mathrm{sec}$ total.

response in the symmetric fuselage mode near $10 \mathrm{~Hz}$ from single to quadruple sweeps. This mode apparently needs the longer dwell time in the single sweep to respond appropriately to an antisymmetric excitation.

Figure 9 shows a symmetric sweep from $3-35 \mathrm{~Hz}$ as compared with a 3-12 $\mathrm{Hz}$ sweep response, both over a 30 -sec time period. Here there is noticeable improvement in the wing bending modal responses below $12 \mathrm{~Hz}$ from the 3 to $12 \mathrm{~Hz}$ sweep, as expected. Notice the similarity between responses in figures 9 and 6 , even though one is a symmetric and the other an antisymmetric exciter sweep. This is a consequence of the phase disparity between exciters mentioned earlier. Finally, a comparison of responses with the exciters moved from their aft position to forward positions on the wingtips is seen in figure 10 . The accelerometer measurement is from the left aft wingtip. Symmetric first wing bending shows an order of magnitude power density increase near $6 \mathrm{~Hz}$, but there is a dramatic decrease in the wing second bending modal responses near $16-17 \mathrm{~Hz}$. These results are indicative of the differences to expect in placement of the exciters relative to output measurements, and how the effective mode shape may influence the results.

To summarize the wingtip excitation test results, despite the erratic performance of the exciters in particularly the high force mode, a voluminous amount of high quality data was accumulated for investigation of differences resulting from exciter test configuration. Test procedure is shown to be a significant parameter in test results, except for sweep duration which did not improve response seriously beyond $30-\mathrm{sec}$. Including multiple 

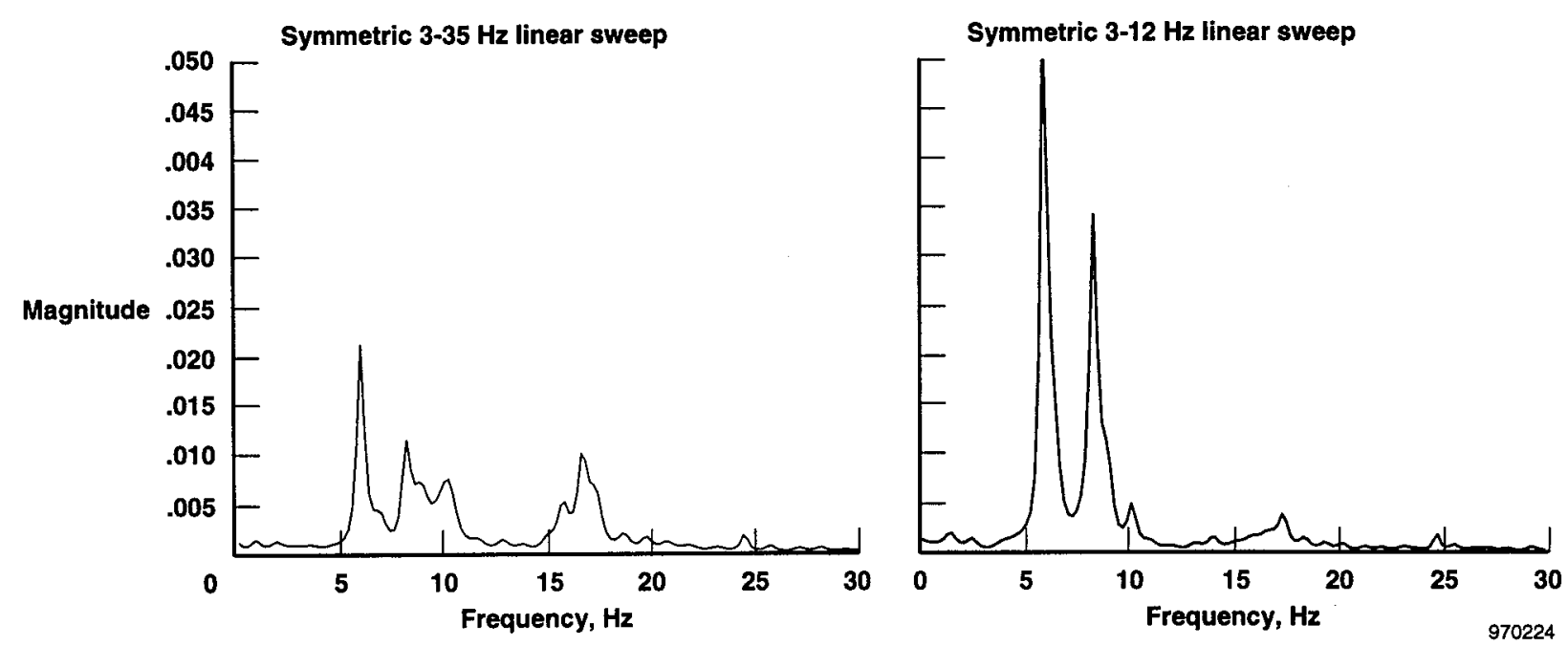

Figure 9. Wingtip accelerometer PSD from symmetric 3-35 Hz (left) and 3-12 Hz (right) exciter sweeps. Sweep duration: 30 -sec.
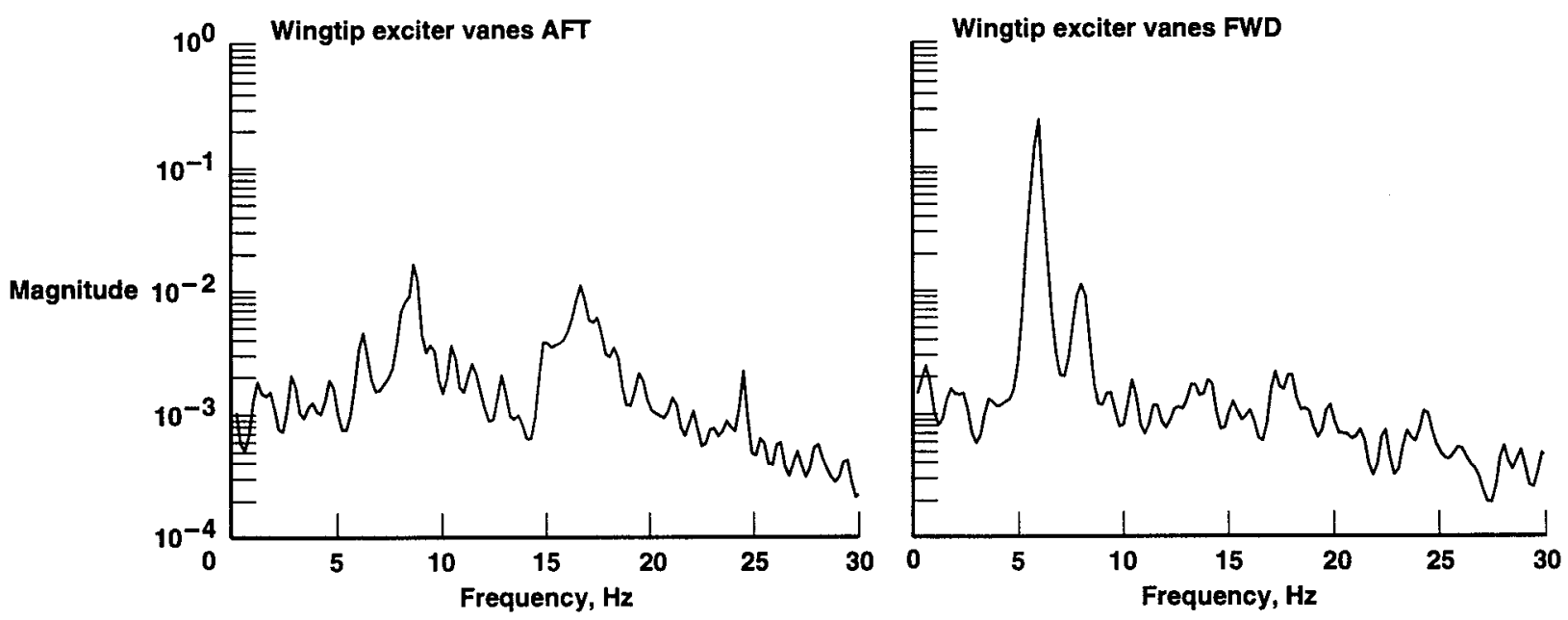

Figure 10. Wingtip aft accelerometer PSD from antisymmetric aft wingtip exciter (left) and forward exciter (right) sweeps. Sweep range: $3-35 \mathrm{~Hz}$, antisymmetric sweep.

sweeps within the same time window offers advantages when including increasing and decreasing data in the same test, as long as sufficient time is allowed for adequate modal response. Exciter placement plays a major role in swapping modal response between the modes because of mode shape. Test repeatability is a problem as long as exciter phase discrepancies exist.

\section{Control Surface Aeroservoelastic Excitation}

\section{System Description}

An important element of the F/A-18 HARV flight system was the on-board excitation system (OBES).
This system was implemented to add programmed digital signals to the control system actuator commands for structural excitation. Inputs up to $25 \mathrm{~Hz}$ were added to the stabilator, aileron, rudder, and pitch and yaw vectored thrust commands. Data was generated with 80 sps OBES commands at from $5^{\circ}$ to $70^{\circ} \mathrm{AOA}$ at $1 \mathrm{~g}$. Accelerometers were located in the aircraft nose, vertical and horizontal tails, wingtips, and near the aircraft center-of-gravity as $80 \mathrm{sps}$ feedbacks to the control system. The feedback measurements are more critical than other structural measurements when using excitation for aeroservoelastic considerations. Verification of closed-loop stability is the primary 
objective. Measurement of signals at the input summing junction (actuator commands) and feedback measurements allow computation of open- and closedloop transfer functions, loop gains, and multivariable stability margins.

\section{Test Results}

Schroeder-phased harmonic signals which produce approximately flat spectral characteristics ${ }^{8,9}$ were compared to $\operatorname{sinc}\left(\frac{\sin x}{x}\right)$ pulses, which theoretically have flat power spectra across a defined frequency range. Contrarily, linear and logarithmic sweeps are known to be deficient at lower and higher frequencies, respectively. Figure 11 displays examples of sinc-pulse and Schroeder-phased inputs from OBES into the surface commands. These signals are stored in flight computer memory. The Schroeder-phased signal is calculated as

$$
x(t)=A \sum_{k} \cos \left(\omega t+\frac{\pi k^{2}}{N}\right)
$$

where $N$ is the number of data and $A$ is a specified amplitude to acquire maximum power under the saturation limits.

Note from the PSDs in figure 12 that the frequency range for the sinc-pulse is $0-25 \mathrm{~Hz}$, whereas the Schroeder-phased signal was programmed for $5-25 \mathrm{~Hz}$.

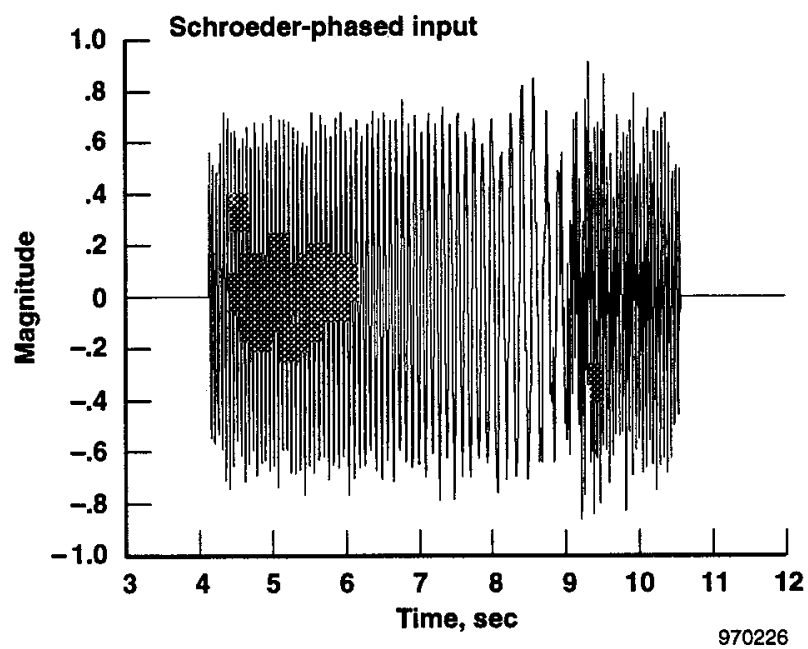

Figure 11. F/A-18 HARV sinc-pulse and Schroeder-phased OBES inputs. Sinc-pulse input (left). Schroeder-phased input (right).
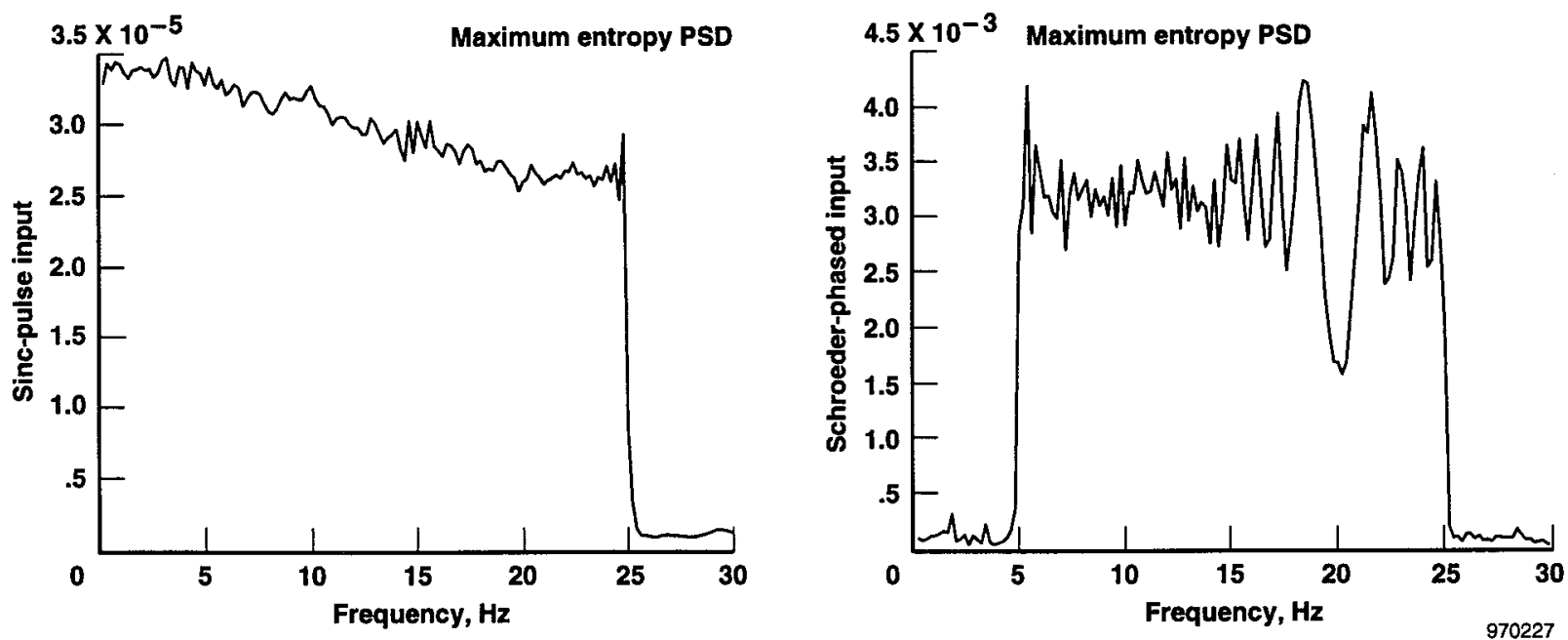

Figure 12. PSDs of sinc-pulse and Schroeder-phased input (note scale difference). Sinc-pulse input (left). Schroederphased input (right). 
More importantly, for inputs close to unity, the Schroeder-phased PSD is two orders of magnitude greater than the sinc-pulse, thereby verifying the property of low peak factor for a given power spectrum (fig. 11). ${ }^{10}$ Peak or crest factor is defined as the difference between signal maximum and minimum values divided by the root-mean-square value of a signal. It is a measure of the flatness of the power spectrum. Low peak factor signals are generally desirable in system testing to avoid large system perturbations. This is an obvious benefit for preventing input saturation while maximizing signal-to-noise ratio.
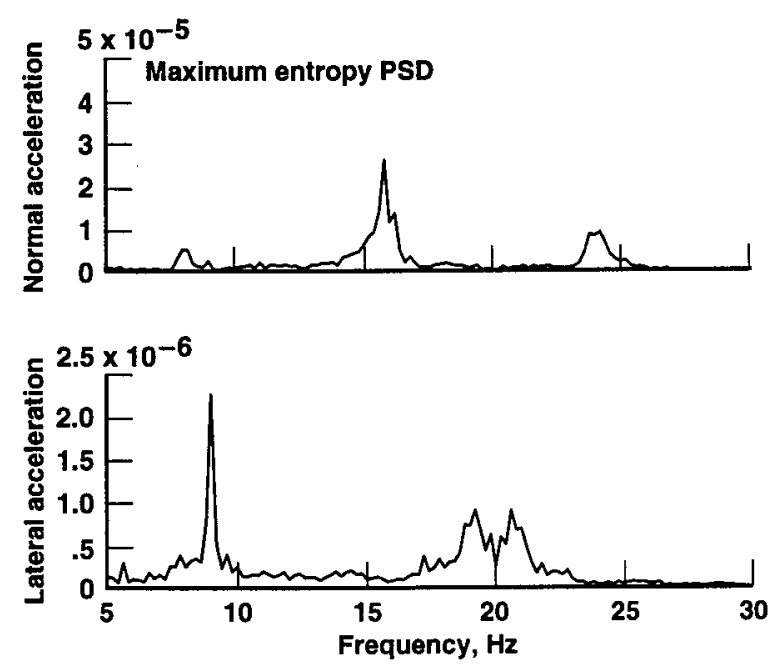

PSDs of normal and lateral acceleration feedback responses are shown in figure 13 for sinc-pulse and Schroeder-phased OBES inputs. Disregarding the order of magnitude difference, the responses are quite similar in terms of modal response. Differences are seen in the large relative response below $10 \mathrm{~Hz}$ from the sinc-pulse lateral acceleration compared with higher frequency modes, and some activity around $20 \mathrm{~Hz}$ from normal acceleration for the Schroeder-phased response that the sinc-pulse does not excite.

Figures 14 and 15 compare transfer functions between sinc-pulsed and Schroeder-phased OBES inputs,
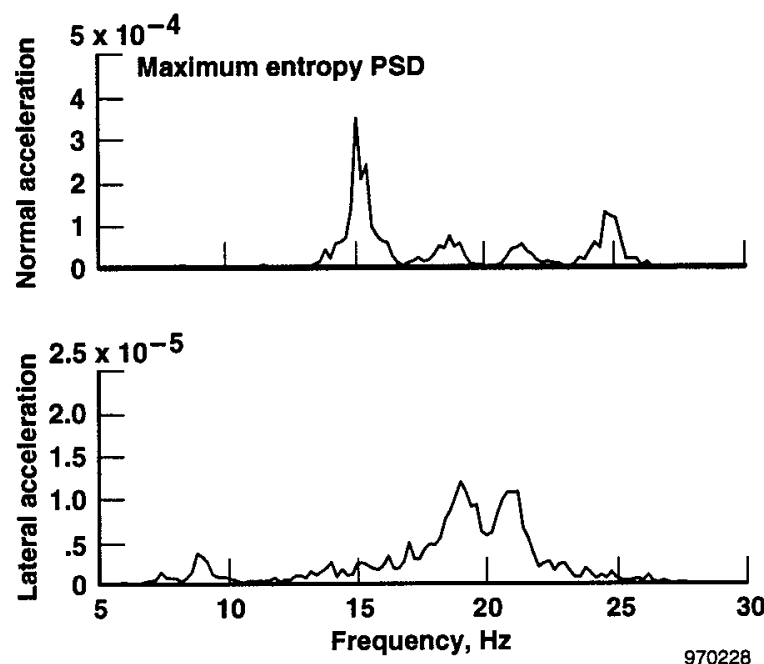

Figure 13. F/A-18 HARV feedback accelerometer responses to sinc-pulse and Schroeder-phased inputs (note scale difference): normal acceleration (top) and lateral acceleration (bottom). Sinc-pulse accelerometer response (left). Schroeder-phased accelerometer response (right).
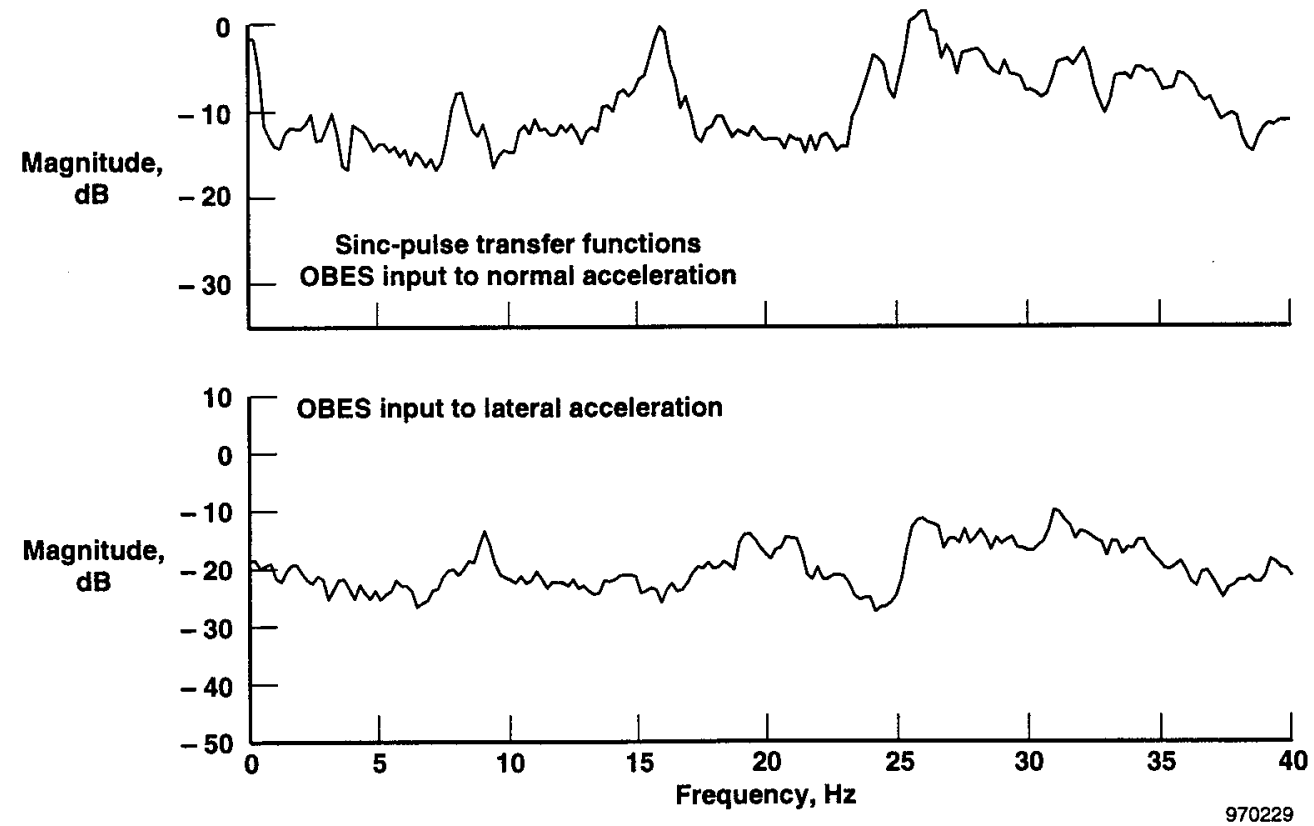

Figure 14. Sinc-pulse transfer functions from OBES input to accelerometer feedbacks. 

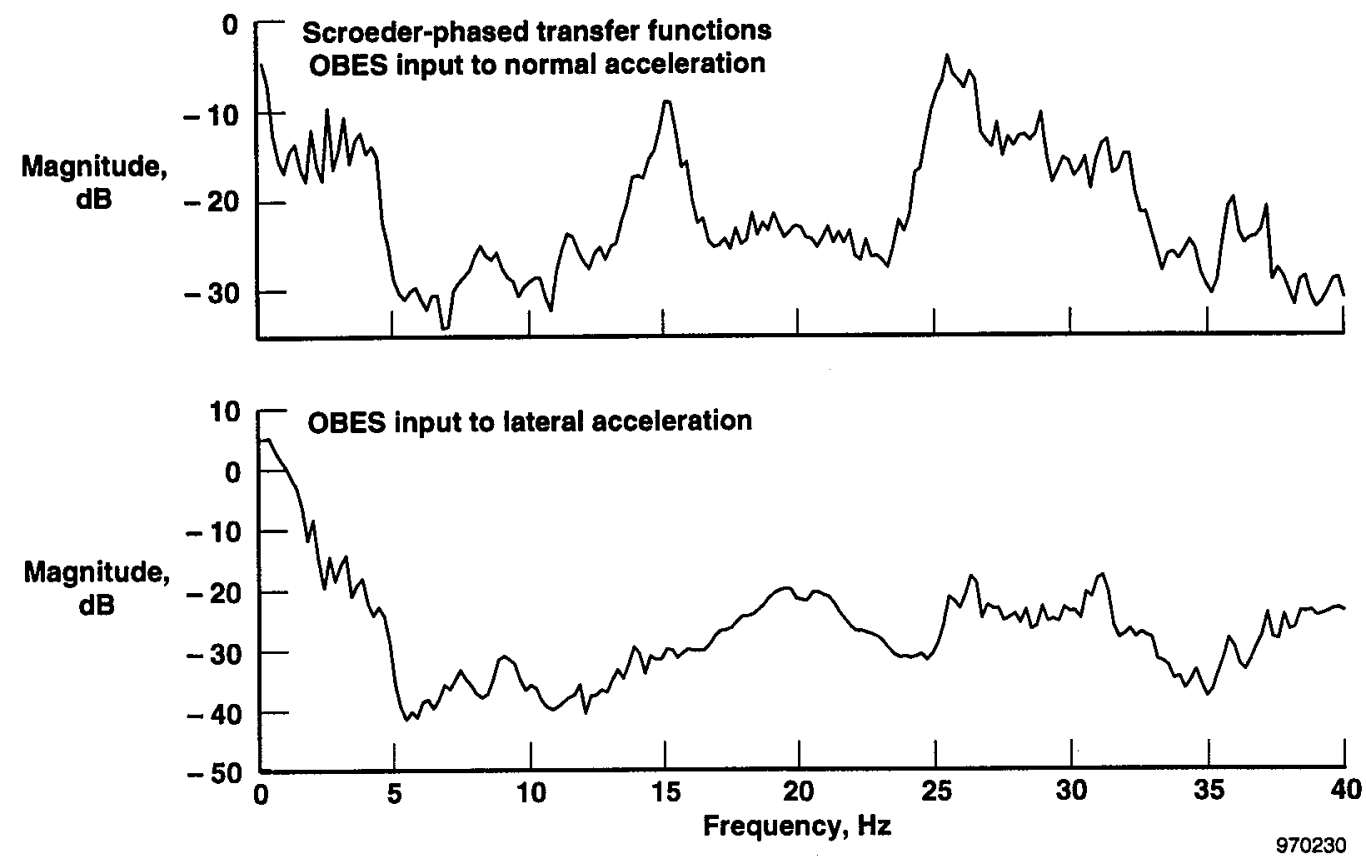

Figure 15. Schroeder-phased transfer functions from OBES input to accelerometer feedbacks.

respectively. OBES inputs are to all the surfaces sequentially, and outputs are normal and lateral acceleration feedbacks. Sinc-pulse transfer functions lack the detail and definition of the Schroeder-phased responses. Magnitudes differ by as much as $20 \mathrm{~dB}$ near $15 \mathrm{~Hz}$. Schroeder-phased responses tend to highlight the signal from the noise and discriminate dominant modal dynamics more readily than sinc-pulse responses. An important aspect of this comparison is the extent to which responses can differ depending on the input. This difference is a critical factor if stability analyses depend on these results. These results are preliminary and more extensive analyses can be found in reference. ${ }^{11}$

\section{Signal Analysis of Aeroelastic Data}

In this section, some signal processing properties of the input signals and accelerometer responses are studied for model validation and flight flutter boundary prediction. Wavelet analyses are highlighted to detect time-varying and nonlinear dynamics. Also, timefrequency applications for enhanced signal processing of vibration data are presented.

\section{Spectral Analysis}

Analysis of transient data violates the assumptions of any FFT-based spectral estimation technique. This technique assumes time-invariance, stationariness, and a signal composed of a sum of infinite sinusoids. Windowing and averaging can help remove some distortion but also add bias errors. For these reasons, autoregressive (AR) spectral estimation is preferred for transient data. In the class of AR spectral estimation methods are the reflection coefficient estimation algorithms. In particular, the maximum entropy method $^{12}$ (MEM) is one method being adopted by NASA Dryden for frequency domain transient signal analysis. MEMs estimate the correlation sequences assuming finite correlation extrapolation to infinity is most random, or has maximum entropy, thereby assuring a positive definite power spectral density function.

Autoregressive coefficients of an all-pole filter representation of the signal are estimated directly from the data without using autocorrelations. Akaike information criteria ${ }^{12}$ are used to determine the autoregressive order of the process (which can also be multichannel, or MIMO) for PSD and transfer function estimation. Model order selection for the AR model of the signal represents the classic tradeoff between higher resolution and decreased variance.

Examples of classical FFT-based PSD estimates compared to MEM estimates are represented in figure 16 with F/A-18 SRA wingtip accelerometer data. These data were acquired at Mach 1.2, an altitude of $30,000 \mathrm{ft}$, and 630 psf dynamic pressure with symmetric excitation. Top plots are left wingtip accelerometers and the bottom plots are right wingtip accelerometers. Comparing the classical (left) with MEM (right) estimates, both methods estimate activity near symmetric wing first bending $(6 \mathrm{~Hz})$, but then the MEM estimates of modal response between $7-10 \mathrm{~Hz}$ is dramatically different from the relatively suppressed 

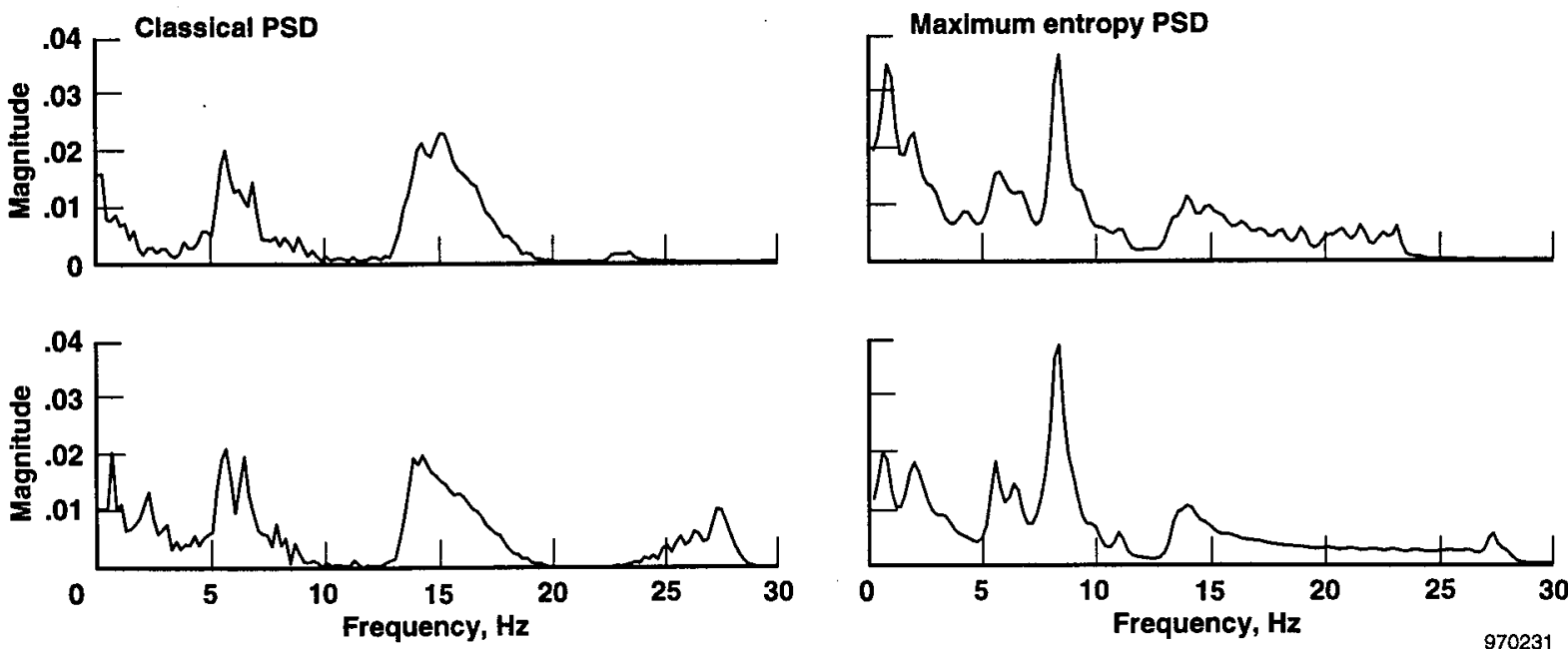

Figure 16. Classical FFT-based PSDs compared to maximum entropy estimates: Left wingtip accelerometer (top) and right wingtip accelerometer (bottom) responses. Classical (left). Maximum entropy (right).

classical response estimates. Symmetric fuselage first bending or antisymmetric wing first bending near $9 \mathrm{~Hz}$ are not even visible in the classical estimates. Alternatively, near $15 \mathrm{~Hz}$ the classical estimates are nearly double the maximum entropy estimates. Between $13-18 \mathrm{~Hz}$ the classical estimates include contributions from wing torsion, second bending, and wing outboard torsion, whereas the MEM estimates are not significant in this range.

These comparisons are intended to highlight the strengths and weaknesses of the two estimates. A reasonable conclusion is that the standard practice of depending on classical estimates is suspect. Other spectral analysis techniques should be supplemented with the standard ones for a thorough complementary analysis.

Frequency domain modal system identification and stability estimation rely on high quality frequency responses to get reliable results. Some estimation techniques attempt to curve fit the data with a parametric representation of the response, and use the parameters to determine stability. Others incorporate frequency response data into a state space identification algorithm and stability is derived from this realization.

To compare the MEM to classical methods in a system identification procedure, a symmetric linear sweep response is used in a transfer function fit procedure for modal frequency and damping estimation. Figure 17
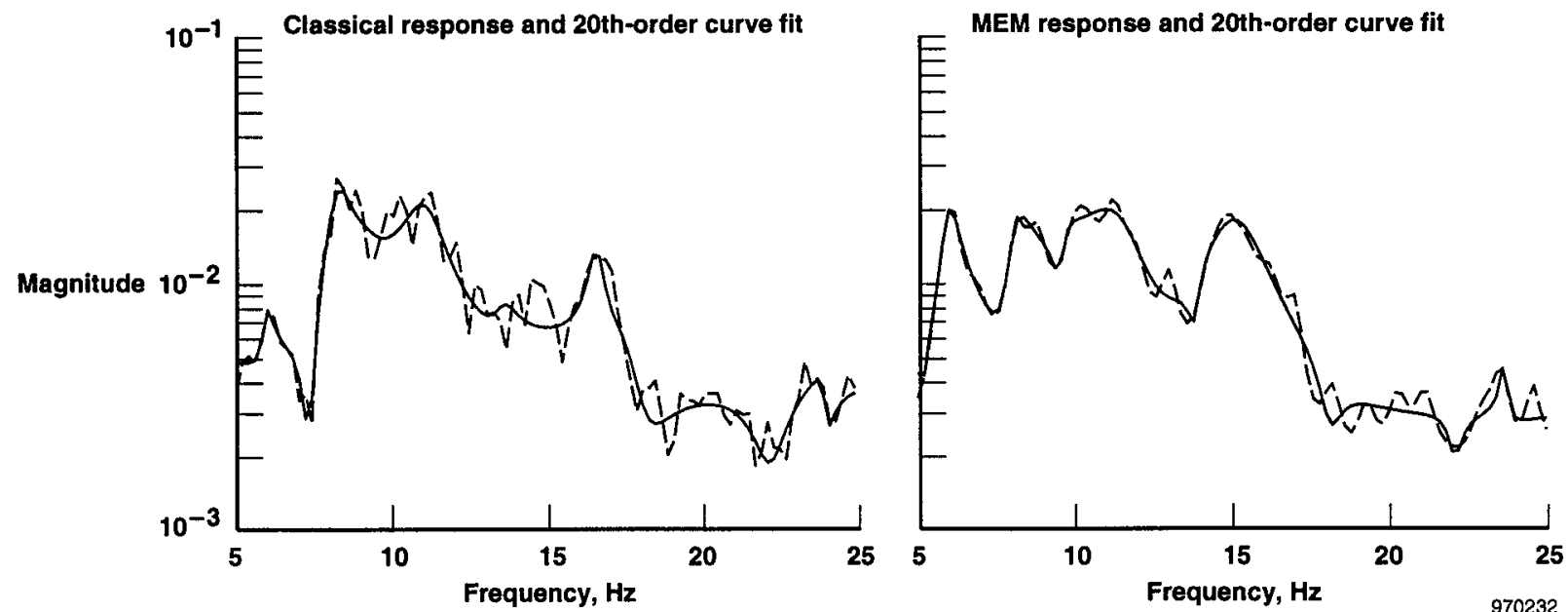

Figure 17. Left forward wingtip accelerometer responses from a symmetric linear sweep using classical (left) and MEM methods (right). Classical response (dashed) and $20^{\text {th }}$-order fit (solid). MEM response (dashed) and $20^{\text {th }}$-order fit (solid). 
(left) is a left forward wingtip accelerometer magnitude response from symmetric F/A-18 SRA excitation computed using a classical method and fit with a $20^{\text {th }}$ order parameterized stable minimum phase transfer function. ${ }^{13}$ In figure 17 (right) the corresponding responses are plotted using a MEM method. The classical response is noisier than the MEM, and does not exhibit the wing first bending modal response of the MEM method near $6 \mathrm{~Hz}$ or symmetric wing first torsion near $15 \mathrm{~Hz}$. However, MEM does not distinguish wing second bending near $17 \mathrm{~Hz}$ as well as the classical method. Figure 18 shows the same comparisons are made with the left aft wingtip accelerometer. Again, the MEM method estimates more modal response near $6 \mathrm{~Hz}$, yet elsewhere the responses are similar.
Frequency and damping ratios computed by fitting the responses with a parameterized transfer function for these respective wingtip accelerometers are displayed in table 4 . Note that the table only addresses symmetric modes even though antisymmetric modes are also being excited (figs. 17 and 18). Since there are some significant differences between classical and MEM estimates, without a truth model an argument can again be made that FFT-based methods need to be complemented with other types of analyses.

\section{Transfer Functions}

Traditional transfer function estimation generally uses what is called the $H_{1}$ estimate, yet it is well known to be biased with input measurement noise. Another
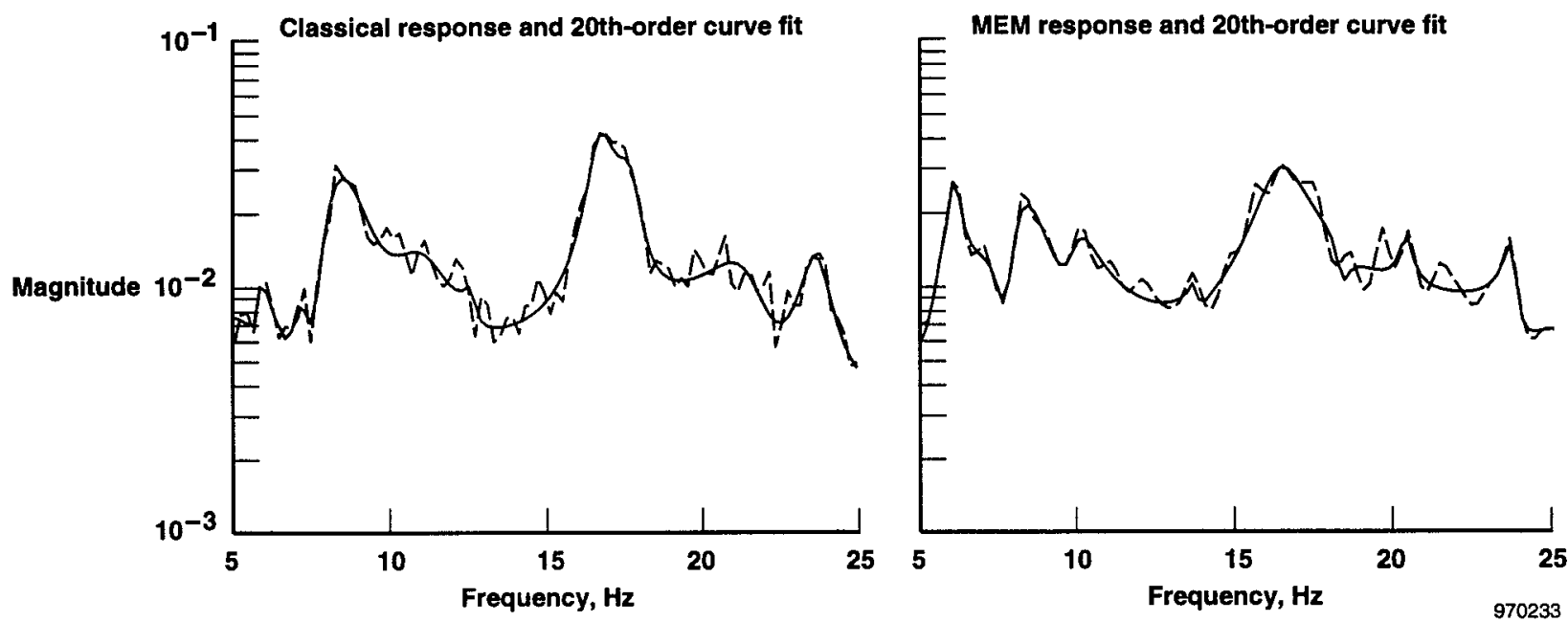

Figure 18. Left aft wingtip accelerometer responses from a symmetric linear sweep using classical (left) and MEM methods (right). Classical response (dashed) and $20^{\text {th }}$-order fit (solid). MEM response (dashed) and $20^{\text {th }}$-order fit (solid).

Table 4. Modal frequencies and damping ratios from F/A-18 SRA wingtip accelerometer data from a symmetric wingtip exciter sweep.

\begin{tabular}{cccccccccrr}
\hline \hline $\begin{array}{c}\text { Symmetric } \\
\text { mode }\end{array}$ & \multicolumn{2}{c}{$\begin{array}{c}\text { Wing } \\
\text { first bending }\end{array}$} & \multicolumn{2}{c}{$\begin{array}{c}\text { Fuselage } \\
\text { first bending }\end{array}$} & \multicolumn{2}{c}{$\begin{array}{c}\text { Wing } \\
\text { first torsion }\end{array}$} & \multicolumn{2}{c}{$\begin{array}{c}\text { Wing } \\
\text { second bending }\end{array}$} & \multicolumn{2}{c}{$\begin{array}{c}\text { Wing } \\
\text { outboard torsion }\end{array}$} \\
\hline Method & FFT & MEM & FFT & MEM & FFT & MEM & FFT & MEM & FFT & MEM \\
\hline \multicolumn{10}{c}{ Frequency, Hz } \\
\hline Wingtip fwd & 6.0 & 6.0 & 11.0 & 11.5 & 13.5 & 13.9 & 16.5 & 15.2 & 17.6 & 18.1 \\
Wingtip aft & 5.8 & 6.0 & 11.0 & 10.0 & 12.5 & 13.7 & 16.6 & 16.4 & 17.6 & 18.3 \\
\hline & \multicolumn{8}{c}{ Damping ratio } \\
Wingtip fwd & 0.06 & 0.10 & 0.12 & 0.17 & 0.06 & 0.04 & 0.03 & 0.12 & 0.08 & 0.06 \\
Wingtip aft & 0.04 & 0.06 & 0.18 & 0.10 & 0.03 & 0.02 & 0.05 & 0.10 & 0.04 & 0.03 \\
\hline \hline
\end{tabular}


estimate, $H_{2}$, is less common since it is biased under output measurement noise and unmeasured external disturbances. $H_{v}$ is the geometric mean of $H_{1}$ and $H_{2}$, where $\left(G_{x y}, G_{y x}, G_{x x}\right.$, and $G_{y y}$ are spectral densities),

- $H_{1}=G_{y x} / G_{x x}$, minimizes error due to noise at output $y$, sensitive to input noise

- $H_{2}=G_{y y} / G_{x y}$, minimizes error due to noise at input $x$, sensitive to output noise

Therefore, for a single input,

$$
H_{v}=\frac{G_{y x}}{\left|G_{y x}\right|} \sqrt{\frac{G_{y y}}{G_{x x}}}=\sqrt{\frac{H_{1}}{H_{2}}}
$$

where $H_{1}<H_{v}<H_{2}$, and the true noise-free transfer function $H_{0}$ also satisfies $H_{1}<H_{0}<H_{2} . H_{v}$ is the so-called robust transfer function estimate ${ }^{14}$ because it is uniformly less biased than either $H_{1}$ or $H_{2}$.

Data generated from the wingtip excitation system is not ideal at either accelerometer outputs or excitation input. Some data corruption results from using strain gauge measurements for the inputs. The response in this case feeds back to the excitation force applied since the strain gage is measuring strain between the responding wingtip and forced vane root. Ideally, the spectral estimates should be referenced to an excitation drive signal (like torque), but this is not available as a measurement. Therefore, for systems in which the input excitation force is unavailable, $H_{v}$ provides optimal transfer function estimation. $H_{v}$ can be degraded by unmeasured external disturbances, but the force input from the exciter is believed to dominate these phenomena.

Frequency responses using the three estimates are plotted in figure 19 using the traditional FFT-based spectral estimates, and in figure 20 using the maximum entropy AR method at the same resolution. These are responses from the left force exciter to a left wingtip accelerometer. They are comparable but differ in some details. Typically, the gap between the $H_{1}$ lower bound and $H_{2}$ upper bound is wider in the MEM response. The MEM response is smoother while distinguishing essential features. Modes near $6 \mathrm{~Hz}, 8-9 \mathrm{~Hz}, 14 \mathrm{~Hz}$, in the $15-20 \mathrm{~Hz}$ range, and even $22 \mathrm{~Hz}$ and $24 \mathrm{~Hz}$ are distinguishable in both classical and MEM responses. Calculating both types of responses gives more credence to the analysis. Otherwise, some of the modes may be misinterpreted. Also notice the dramatic differences that can result between $H_{1}$ or $H_{2}$, and $H_{v}$.

Admittedly, there are different techniques for analyzing specific types of excitation data, (random, periodic or transient) with classical methods. But the AR methods are not subject to restrictions depending on

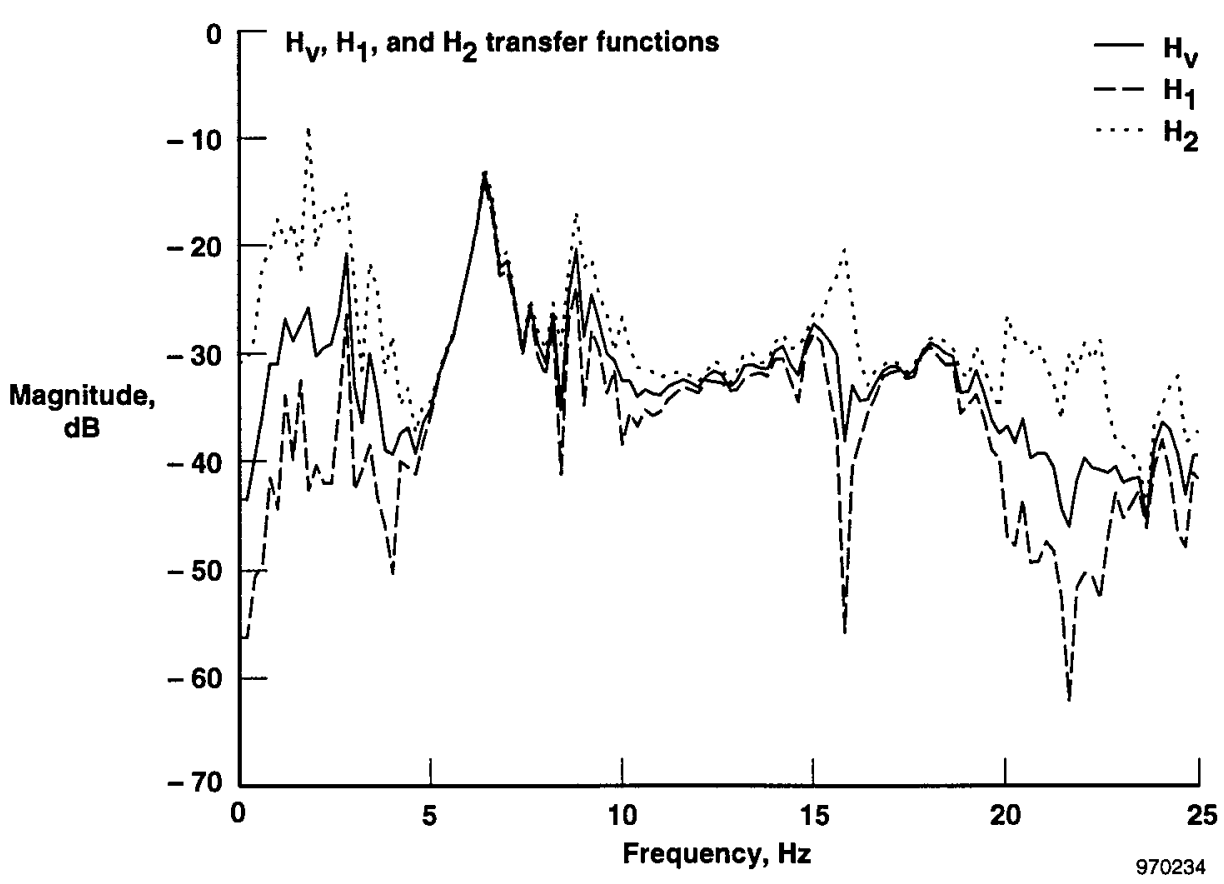

Figure 19. Classical FFT-based transfer functions $H_{v}, H_{1}$, and $H_{2}$. 


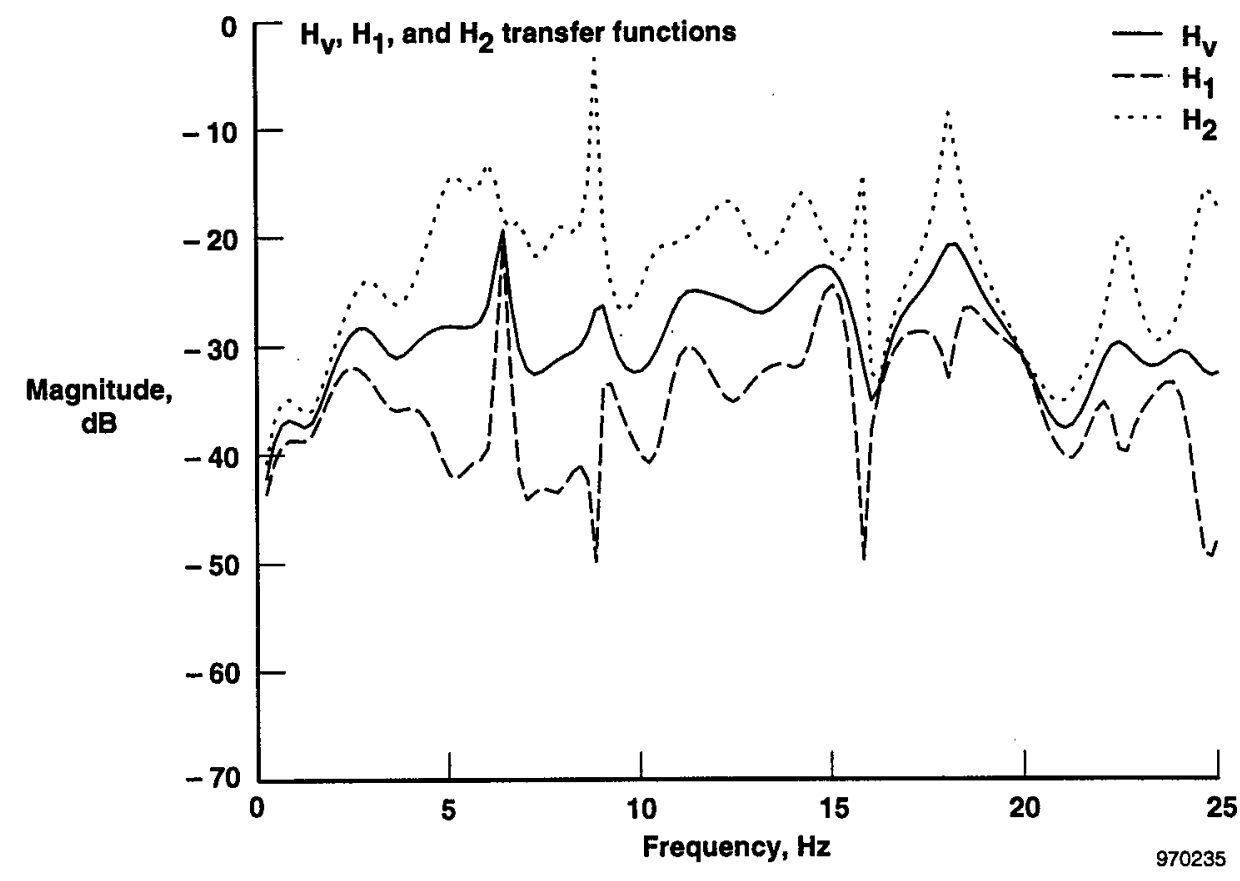

Figure 20. Maximum entropy transfer functions $H_{v}, H_{1}$, and $H_{2}$.

the type of data, so alterations from averaging and windowing are unnecessary.

\section{Time-Frequency Analysis}

Analysis of the frequency content of a signal $x(t)$ traditionally uses the Fourier transform which projects the signal onto sinewave basis functions of infinite duration for stationary signals. This transform is not localized in time. For time-varying signals a transform of the form

$$
T(x(t))=X(t, \omega)
$$

is needed to locate instantaneous frequencies in $x(t)$. Such a transform is limited in resolution by the Hiesenberg uncertainty principle $\Delta \omega \cdot \Delta t \geq 2$. Resolution problems resulting from the uncertainty principle can be minimized by a time-frequency decomposition called the wavelet decomposition. ${ }^{15}$

The wavelet decomposition performs an orthonormal projection of the signal onto functions that are adapted to the frequency resolution needed. A continuous wavelet transform $(C W T)$ is defined as

$$
C W T(\tau, a)=\frac{1}{\sqrt{a}} \int_{-\infty}^{\infty} x(t) h^{*}\left(\frac{t-\tau}{a}\right) d t
$$

where $h_{a, \tau}(t)=h\left(\frac{t-\tau}{a}\right)$ is the wavelet basis function, * is its complex conjugate transpose, $\tau$ is the local time, and $a$ is a scale or dilation parameter set to match the level of resolution desired. With the CWT the time resolution is arbitrarily good at high frequencies and the frequency resolution becomes arbitrarily good at low frequencies, within the limits of the uncertainty principle. Time-frequency analyses attempt to minimize the effects of this resolution problem by using a priori knowledge of the signal properties, or adapting the resolution to the signal. ${ }^{16,17}$

A procedure has been developed ${ }^{6}$ to filter unwanted distortions and extract desired features from the input excitation and output structural response data of the F/A-18 SRA and HARV aircraft. These feature filtered data are then used to compute cleaned signals for transfer functions and system identification algorithms.

An example of filtering the undesirable features of more complicated input-output signals using a timefrequency representation will be a double logarithmic sweep from the F/A-18 SRA excitation system. A scalogram of the original input signal is shown in figure 21 (top). Harmonics from the strain gage input measurement can be readily detected in the timefrequency map as the darker portions of the image. 
These areas in the map represent large amplitude $C W T$ coefficients. The harmonics indicate nonlinear exciter vane response from the rotating slotted cylinders at the wingtips, which is deemed undesirable for subsequent linear state-space identification methods. Therefore, the input signal is modified by extracting the desired timefrequency map from the scalogram to retain the commanded input signal from the main harmonic (fig. 21 (bottom)).
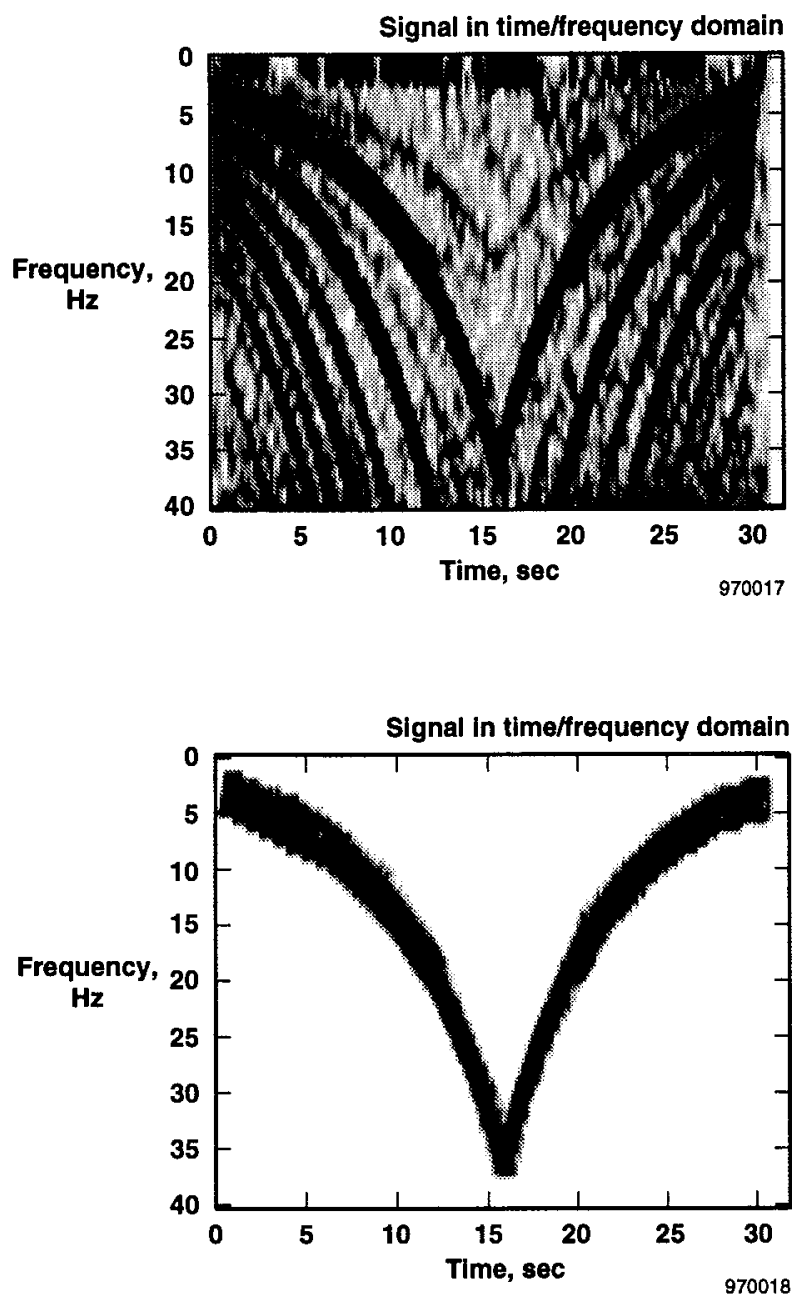

Figure 21. Scalogram of original double logarithmic exciter input and feature filtered input. Scalogram of original exciter input signal (top). Scalogram of feature filtered exciter input signal (bottom).

These CWT coefficients are then used to reconstruct the time domain input signal by inverse transforming at each frequency $\omega$ back to the time domain. Figure 22 shows the original signal in the top plot, including harmonics. Reconstruction from the scalogram of figure 21 (top) is shown in the middle plot. Notice the reconstruction is not exact since there is some distortion in the wavelet processing procedure. Finally, the feature filtered signal from figure 22 (middle) is reconstructed with only the main harmonic, as shown in the bottom plot of figure 22 .

Similar procedures are performed on the accelerometer measurements and transfer functions are computed using the feature filtered data sets from the F/A-18 SRA. Transfer functions from both exciter inputs (left and right columns, respectively) to an accelerometer output are plotted in figure 23. The top four plots result from classical Fourier methods, and the corresponding bottom plots are results of using the feature filtered timefrequency method. As shown, very general maps in the time-frequency plane can be effectively filtered in this manner. More details concerning the development and application of wavelet filters to analysis of F/A-18 SRA aeroelastic data can be found in references. ${ }^{6}$

\section{Flight Flutter Prediction}

Several modal estimation algorithms have been applied to flight flutter testing in both frequency and time domain ${ }^{18,19}$ for extracting stability estimates and detecting time-varying and/or nonlinear dynamics. No algorithm has been unanimously accepted in the aeroelastic community because of 1) problems with estimation of closely spaced modes or assuring stable estimates for stable systems, 2) assumption of time invariance, linearity, or stationariness, 3 ) sensitivity to type of input or noise levels, 4) lack of technique for estimating error bounds, and, 5) computational complexity. In an attempt to qualify the relative merit of the methods with actual flight data, a non-exhaustive list of algorithms in table 5 is being considered for evaluation at NASA Dryden for usefulness in flutter testing. The frequency domain subspace identification methods combined with time-frequency multiscale wavelet techniques are the most promising algorithms. $6,20,21$

Modal damping is unfortunately the most popular parameter to track for determining proximity to the flutter boundary. It can be a very poor indicator of impending instability as it depends on critical flight parameters (Mach, $\bar{q}$ ) in a highly nonlinear fashion. Tests performed with different input signals, and the very common occurrence of nonrepeatability at identical test conditions, can change damping estimates dramatically using state-of-the-art identification schemes. 

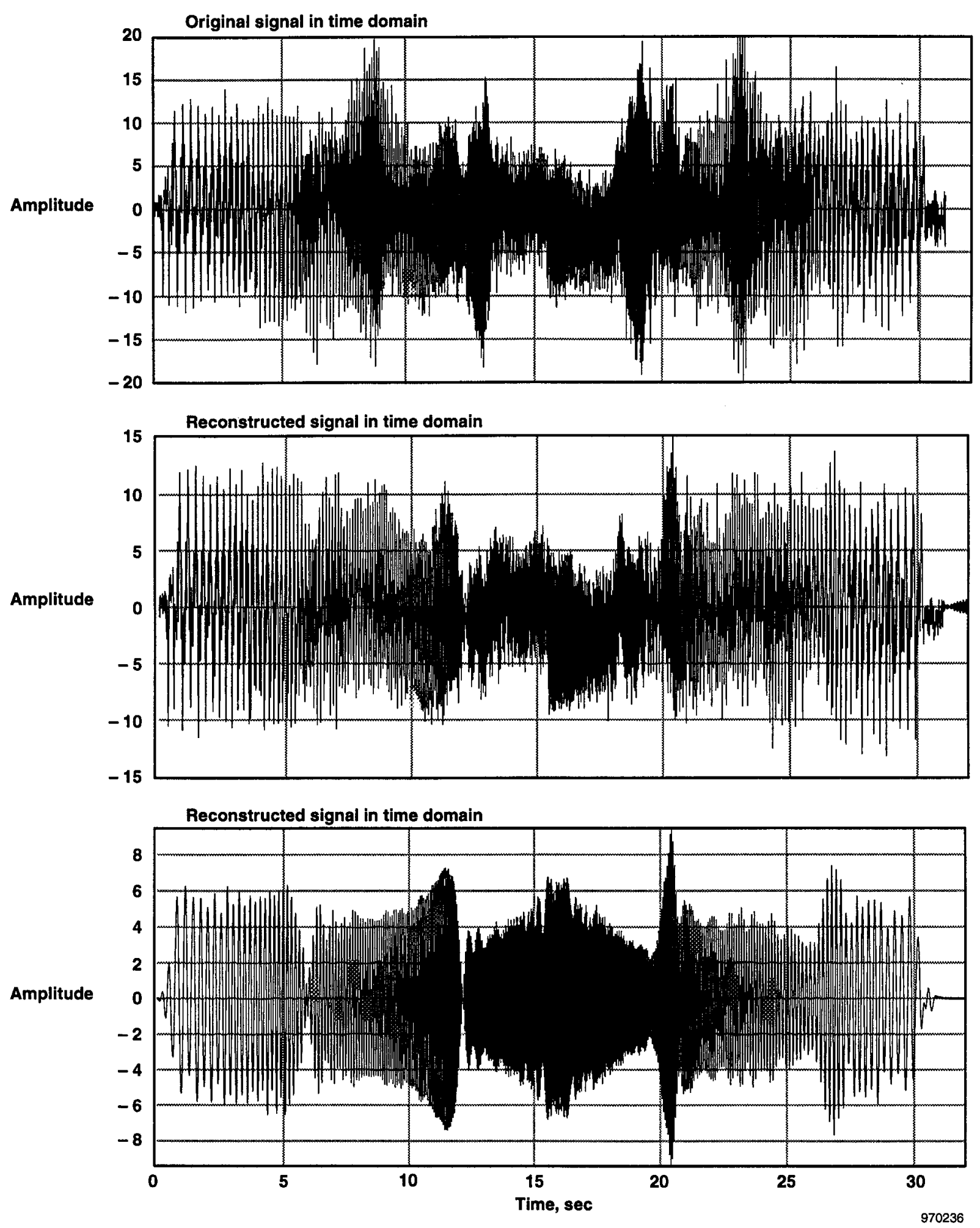

Figure 22. Original F/A-18 SRA exciter input signal (top), reconstruction of original signal (middle), and reconstruction of feature filtered input signal (bottom). 

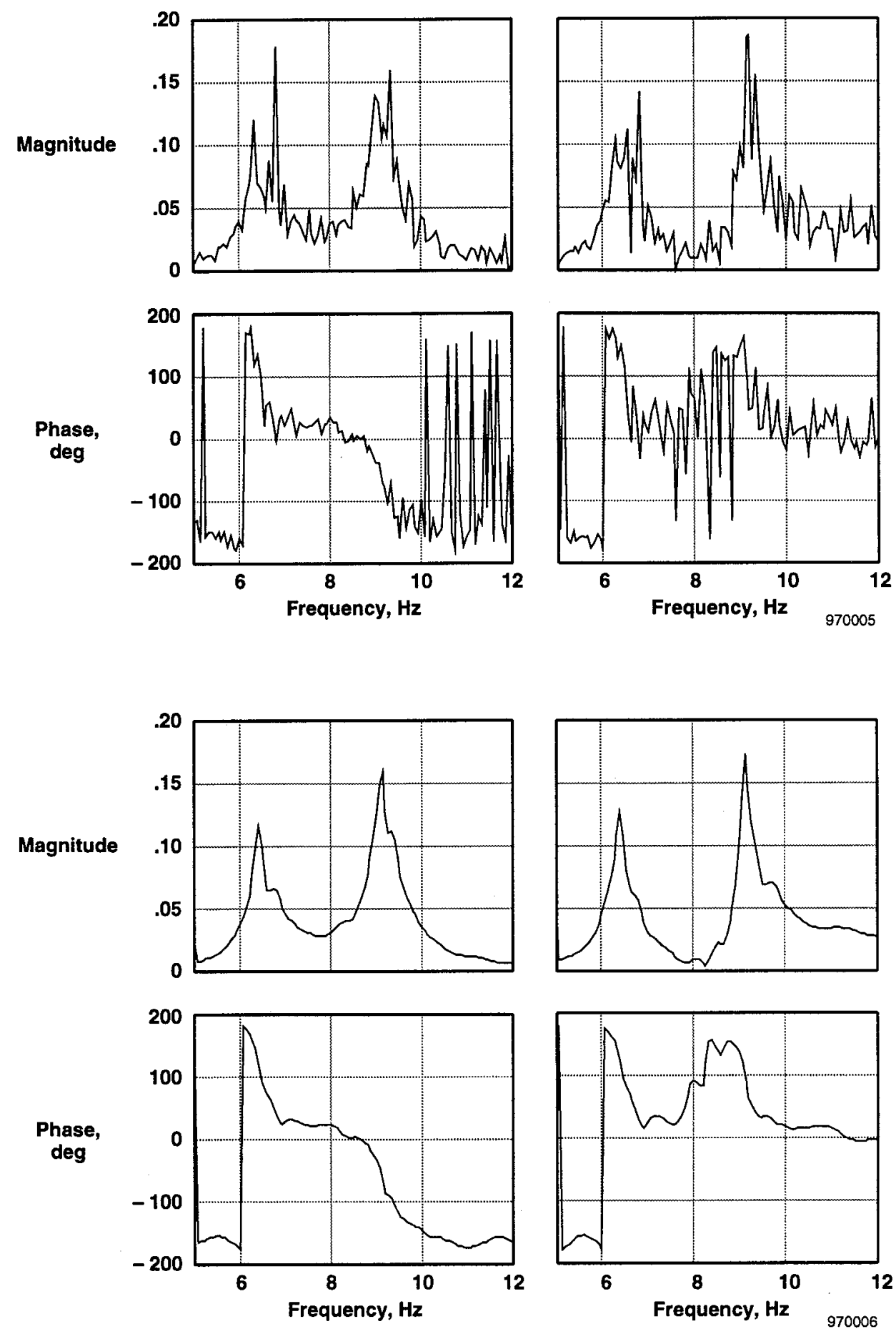

Figure 23. Transfer functions computed with classical Fourier technique and feature-filtered time-frequency method: Left F/A-18 SRA exciter input to wingtip accelerometer output (left). Right F/A-18 SRA exciter input to wingtip accelerometer output (right). Classical Fourier transfer functions (top). Time-frequency generated transfer functions (bottom). 
Table 5. Survey of modal estimation algorithms for aeroelastic applications.

\begin{tabular}{|c|c|}
\hline Frequency domain & Time domain \\
\hline Spectral analysis & Time series analysis \\
\hline FFT/correlation methods ${ }^{22}$ & Correlation/null-space methods ${ }^{23,24,25}$ \\
\hline Maximum entropy/maximum likelihood ${ }^{12,26}$ & Linear prediction (LS, MLE, IV, PEM) ${ }^{27}$ \\
\hline$l_{2}$ and $l_{\infty}$ curve fitting ${ }^{28,29,30,31}$ & Total least squares (TLS) ${ }^{32}$ \\
\hline Orthogonal polynomials $s^{33,34}$ & Total least norm (TLN) $)^{35}$ \\
\hline \multicolumn{2}{|c|}{ Robust identification $^{36}$} \\
\hline$H_{\infty}$ Norm-bounded $\mathrm{ID}^{37}$ & Worst-case input-output $l_{1} \mathrm{ID}^{38}$ \\
\hline \multicolumn{2}{|c|}{ Subspace identification $^{39,40}$} \\
\hline \multicolumn{2}{|c|}{ Realization-based methods } \\
\hline Transfer Function Fitting (TFF) ${ }^{41}$ & ERA/OKID ${ }^{42}$ \\
\hline Auto-Cross-Spectra Fitting (ACSF) $)^{41}$ & Q-markov cover ${ }^{43}$ \\
\hline State-Space Frequency Domain (SSFD) ${ }^{44}$ & Stochastic Realization (SRA) ${ }^{45}$ \\
\hline \multicolumn{2}{|c|}{ Direct subspace identification } \\
\hline FORSE, ${ }^{20,46,47}$ McKelvey $^{21}$ & ORSE, ${ }^{48} \mathrm{~N} \mathrm{SID}^{39}$ \\
\hline \multicolumn{2}{|c|}{ High order spectral analysis ${ }^{49}$} \\
\hline Frequency-time mu & e wavelets ${ }^{15,50,51}$ \\
\hline
\end{tabular}

\section{Robust Flutter Boundary Prediction}

A $\mu$-based measure of flutter boundary prediction is proposed which has the following important desirable features:

1. Robust (reliable) identification in the presence of estimation model uncertainty

2. Quantification of the error bounds because of unmodeled dynamics, uncertain parameters and noise

3. Well-behaved stability measured as a function of critical flight parameters (Mach, $\bar{q}$ )

4. Incorporation of model structure into the identification procedure (prior knowledge)

5. Dependence on a minimum amount of test points for extrapolation to the flutter boundary

6. Algorithmic simplicity for on-line implementations

7. Realistic assumptions

This $\mu$-based flutter prediction method with these seven advantages to compute flutter instability boundaries is of obvious benefit to the aeroelastic community. In this method, flight data is incorporated into the model validation process to account for any differences between the model and the aircraft. Robust worst-case flutter margins are computed to directly account for variations in the data (non-repeatability) and model parameter uncertainty. These robust flutter margins are generated by forming realistic uncertainty operators that ensure that a family of models includes the actual aircraft dynamics. The procedure can greatly improve the efficiency and safety of an envelope expansion with accurate and confident identification. Data from safe and benign flight conditions are used to predict flutter boundaries.

Critical elements for this technique are model validation and robust stability measures. Systeminduced norms are used for model error descriptions to measure the 'closeness' of systems in the context of robust control. ${ }^{38,52}$ The key question for model validation is this:

Given the available data and model, does there exist a perturbation within the range of allowed norm-bounded uncertainty such that the model describes the data?

A nonconservative approach to this issue is to find the smallest perturbation such that the data fits the model. Robust flutter prediction poses this additional question: 
Given the available data and models, what is the smallest norm-bounded perturbation of the current flight condition that can drive the system to become unstable?

This is the robust stability aspect of the problem. In this context, structuring the error in the aeroelastic model and applying model validation concepts using flight-derived uncertainty models avoids relying on damping estimates as a measure of modal stability. ${ }^{53,54}$ Here the structure of the aeroelastic model is preserved, and uncertainty enters the system in a prescribed manner. Damping estimates are replaced by the stability $\operatorname{margin} \mu$.

These robust stability concepts are used to parameterize an aeroelastic model with dynamic pressure at specific Mach numbers, and introduce uncertainty structure to account for model inaccuracy. Figure 24 represents a robust stability parameterization over $\bar{q}$ of the state-space aeroelastic system. The nominal flutter margin is that value of $\bar{q}$ which results in aeroelastic instability.

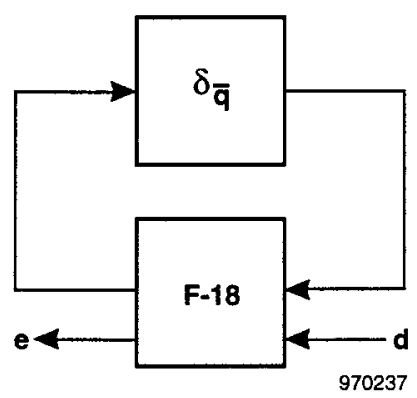

Figure 24. Robust stability parameterization over $\bar{q}$ for nominal flutter margin.

For the F/A-18 SRA, numerous data sets from 40k, $30 \mathrm{k}$, and $10 \mathrm{k} \mathrm{ft}$ altitude for each Mach number (table 3 ) are analyzed to determine whether the data is accounted for by the model. If not, the model is adjusted by increasing the real parameter uncertainty in modal frequency and damping. After this procedure, other unmodeled dynamic uncertainty is adjusted to include multiple data sets at a particular flight condition (Mach, $\bar{q}$ ).

An uncertainty description consisting of modal uncertainty, $\Delta_{\text {modes }}$, and input multiplicative uncertainty, $\Delta_{i n}$, is used to account for errors and unmodeled dynamics resulting in the system depicted in figure 25. This model is created for each flight condition, from all the available flight data responses. Now the model envelopes all the aeroelastic dynamics of the aircraft at a particular Mach number. Since the model is now validated by the flight data, realistic robust flutter margins can be computed.

Flutter points are derived with respect to dynamic pressure and the system uncertainty model derived from the data, using the structured singular value, ${ }^{13} \mu$. This worst-case stability boundary guarantees stability within the range of system uncertainty deduced from the mismatch between model and data.

Advantages of this $\mu$-based robust flutter boundary prediction method are as follows:

- Model validation can be cast in the frequency or time domain 52,55

- Parameter identification uncertainty can be incorporated into the model

- Identification error estimates are not essential

- Generalized uncertainty descriptions are admissible (real, complex, time-varying, nonlinear)

- Stability norms generally behave smoothly at instability boundaries

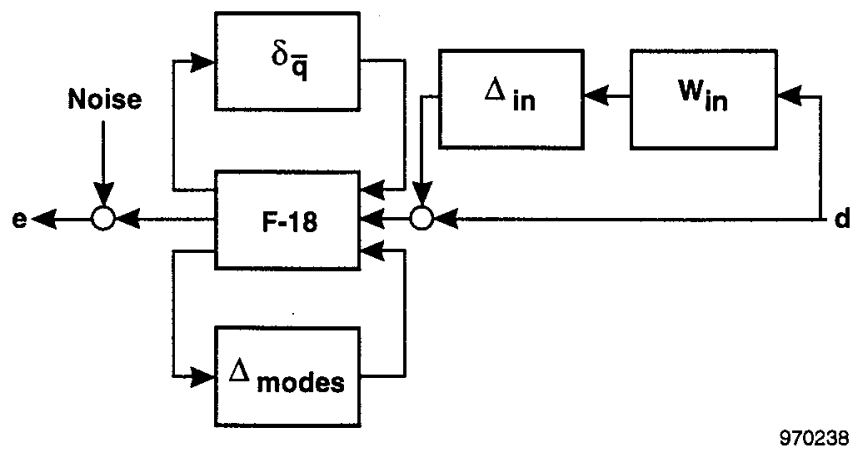

Figure 25. F/A-18 uncertainty block diagram for robust flutter margin. 
- Some conservatism for flight safety will always exist (nominal vs. robust flutter boundary)

- Aeroservoelastic stability is analyzed in the same framework

- Procedure can be tuned for on-line analyses

- Naturally extends to robust control synthesis for flutter suppression

If the uncertainty model is invalidated at some flight condition, either the identification procedure must be revisited, the uncertainty description modified accordingly, or both. While the model is not invalidated, it remains a robust stability measure. A companion paper $^{53}$ details the procedure for using F/A-18 SRA aeroelastic data in prediction of the aeroelastic stability boundary.

\section{Robust Stability Results}

Flutter prediction computation uses the finite element and unsteady aerodynamic $p k$ solutions computed from the STARS ${ }^{56}$ code. Figures 26 and 27 represent this flutter boundary with solid lines for symmetric and antisymmetric modes, respectively. These are the socalled 'matched point' flutter solutions which account for actual atmospheric conditions in the solution process.
Circled points in the figures are solutions of the minimum destabilizing perturbation of dynamic pressure from a nominal condition using $\mu$ (fig. 26 and 27). These points are nominal flutter solutions using the $\bar{q}$ parameterization of figure 24 for each Mach number with no uncertainty operators in the stability margin computation. A good match with the solid lines indicates that using the generalized aerodynamic forces at a nominal condition will extrapolate to the proper analytical result from the $\bar{q}$ parameterization. The only exception where matches are not optimal occurs around the transonic area where the aeroelastic $p k$ solutions are most sensitive.

Finally, the analytical flutter points are compared with the robust structured singular value solutions computed with respect to the uncertainty description $\Delta_{\text {modes }}, \Delta_{\text {in }}$ of figure 25 . Using all available flight data, model validation and robust stability computations result in the dashed lines of these figures (figs. 26 and 27). Robust results are more conservative, as expected, due to the uncertainty model updates from incorporation of the data.

\section{Conclusions}

Improvements in aeroelastic and aeroservoelastic flight testing have been addressed. F/A-18 SRA and HARV aircraft provide valuable data for analysis of

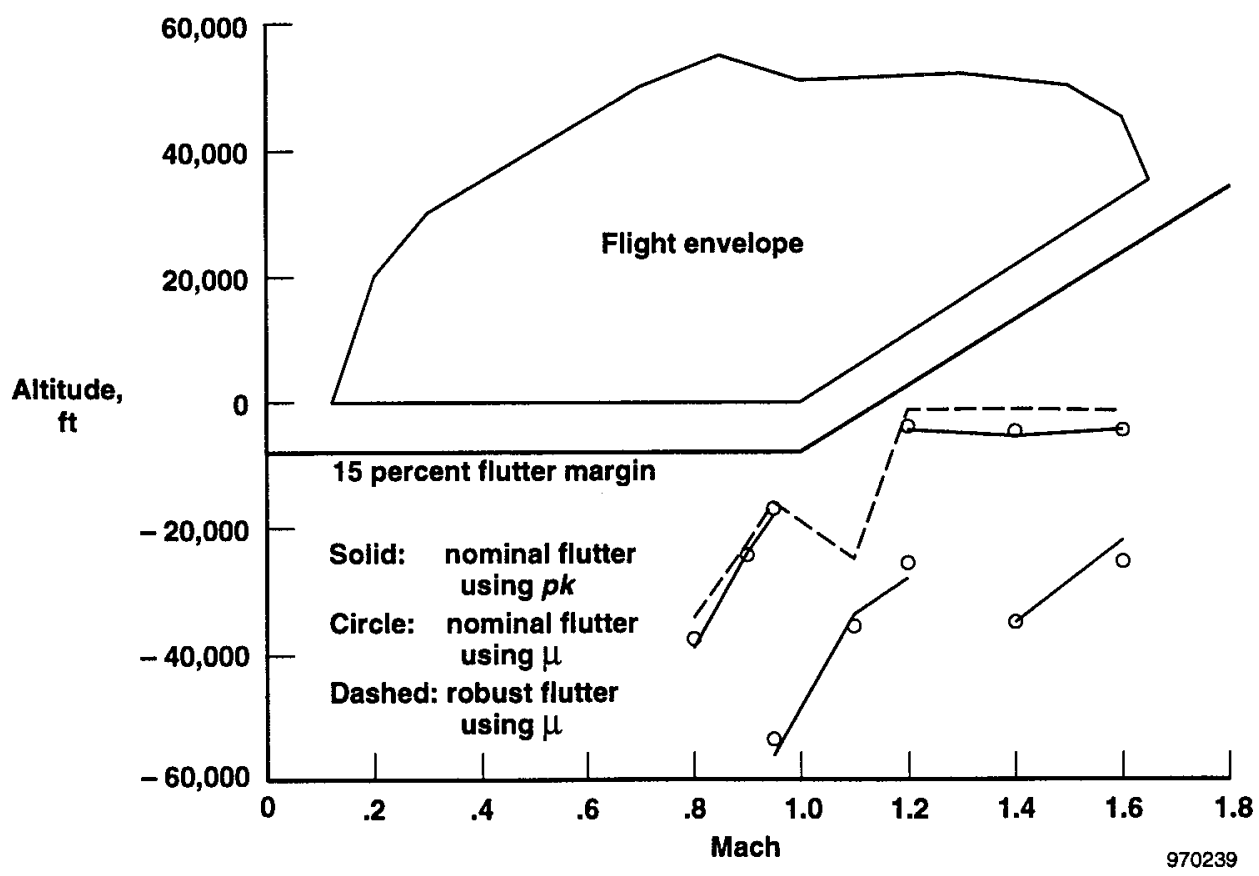

Figure 26. Nominal and robust flutter points-symmetric modes. 


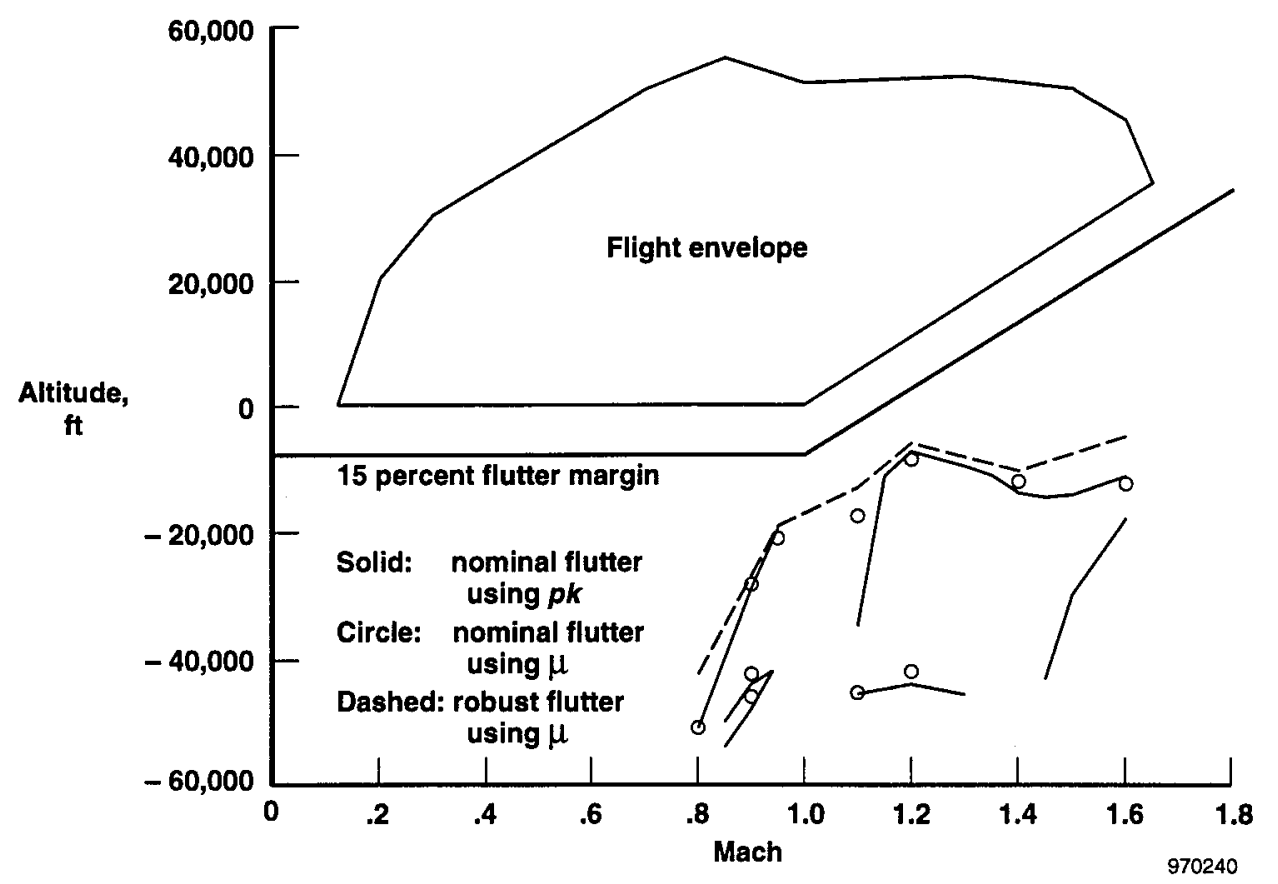

Figure 27. Nominal and robust flutter points-antisymmetric modes.

excitation mechanisms, model estimation algorithms, and stability boundary prediction. External excitation for aeroelastic research was conducted on the F/A-18 SRA and on-board signal generation was used on the F/A-18 HARV for aeroservoelastic investigation. However, data from excitation systems is only as reliable as the system performance, so excitation system anomalies need to be accounted for when using estimation algorithms for stability estimates. Classical spectral estimates are suspect in a time-varying or nonstationary environment, so parametric maximum entropy spectral estimates are suggested as an alternative to supplement classical analyses. Furthermore, advanced procedures in timefrequency methods have been presented which will assist in detecting and compensating for data distortion, such as nonlinearity, before modal analysis. Time-frequency wavelet analyses have also been exploited for detecting departures from time-invariance, stationariness, and noise assumptions. Such applicable data processing techniques, tuned for the particular test environment, are desired for enhanced on-line analyses.

Modal identification must account for divergence from algorithmic assumptions in the form of error bounds. A method which accounts for such uncertainties in the data and analysis results has been introduced. Modal damping as an unreliable stability predicter is replaced by a robust $\mu$-based stability margin for more confident and efficient stability boundary prediction. Identification consistent with the uncertainty structure in an aeroelastic model provides an explicit measure of stability in a modern robust control framework. Robust model validation accounts for the uncertainty structure, guaranteeing that any system will remain stable within a confidence bound. Therefore, model validation techniques are exploited to develop structured uncertainty models consistent with the data. Stability is guaranteed within the uncertainty deduced from the data. F/A-18 SRA data is used to demonstrate worst-case flutter boundary prediction using this method. This procedure can be tuned for robust aeroelastic and aeroservoelastic on-line stability prediction.

\section{References}

${ }^{1}$ Brenner, Martin J., Aeroservoelastic Modeling and Validation of a Thrust-Vectoring F/A-18 Aircraft, NASA TP-3647, Sept. 1996.

\footnotetext{
${ }^{2}$ Vernon, Lura, In-Flight Investigation of a Rotating Cylinder-Based Structural Excitation System for Flutter Testing, NASA TM-4512, June 1993.

${ }^{3}$ Weiss, F., J. Schweiger, and, Dr. H. Hönlinger, Flutter Flight Test of the RANGER 2000 Aircraft, AGARD-CP-566, Nov. 1995.

${ }^{4}$ Schippers, P. and A.J. Persoon, Flight Flutter Testing of a Turbo-Prop Aircraft by Using External Excitation Devices, AGARD-CP-566, Nov. 1995.
} 
${ }^{5}$ Shirley, B.M. and E.I. Anderson, US Air Force/DEI Flutter Exciter Test Program, AGARD-CP-566, Nov. 1995.

${ }^{6}$ Brenner, Martin J. and Eric Feron, "Wavelet Analyses of F/A-18 Aeroelastic and Aeroservoelastic Flight Test Data," $38^{\text {th }}$ AIAA Structures, Structural Dynamics, and Materials Conference, Apr. 1997.

${ }^{7}$ Lind, Rick and Marty Brenner, "Incorporating Flight Data into a Robust Aeroelastic Model," submitted to AIAA J. of Aircraft, Oct. 1996.

${ }^{8}$ Schroeder, M.R., "Synthesis of Low-Peak-Factor Signals and Binary Sequences of Low AutoCorrelation," IEEE Transactions on Information Theory, vol. 16, pp. 85-89, Jan. 1970.

${ }^{9}$ Young, Peter and Ronald J. Patton, "Comparison of Test Signals for Aircraft Frequency Domain Identification," AIAA J. of Guidance, Control and Dynamics, vol. 13, no. 3, Mar. 1989.

${ }^{10}$ Van der Ouderaa, Edwin, Johan Schoukens, and Jean Renneboog, "Peak Factor Minimization of Input and Output Signals of Linear Systems," IEEE Transactions on Instrumentation and Measurement, vol. 37, no. 2, June 1988.

${ }^{11}$ Brenner, Martin J., Rick Lind, and David F. Voracek, "Aeroservoelastic Model Identification with Multiple Inputs," abstract submitted to 1997 AIAA Atmospheric Flight Mechanics Conference, Jan. 1997.

${ }^{12}$ Marple, S. Lawrence, Digital Spectral Analysis with Applications, Prentice-Hall, 1987.

${ }^{13}$ Balas, G.J., John C. Doyle, Keith Glover, Andy Packard, and Roy Smith, $\mu$-Analysis and Synthesis Toolbox, MUSYN Inc. and The MathWorks, Inc., Apr. 1991.

${ }^{14}$ Vold, Havard, John Crowley, and G. Thomas Rocklin, "New Ways of Estimating Frequency Response Functions," Sound and Vibration, Nov. 1984.

${ }^{15}$ Strang, Gilbert and Truong Nguyen, Wavelets and Filter Banks, Wellesley-Cambridge Press, 1996.

${ }^{16}$ Herley, Cormac, Jelena Kovačević, Kannan Ramchandran, and Martin Vetterli, "Tilings of the TimeFrequency Plane: Construction of Arbitrary Orthorgonal Bases and Fast Tiling Algorithms," IEEE Transactions on Signal Processing, vol. 41, no. 12, Dec. 1993.
${ }^{17}$ Jones, Douglas L. and Richard G. Baraniuk, "An Adaptive Optimal-Kernel Time-Frequency Representation," IEEE Transactions on Signal Processing, vol. 43, no. 10, Oct. 1995.

${ }^{18}$ Cooper, J.E., "Parameter Estimation Methods for Flight Flutter Testing,” AGARD-CP-566, Nov. 1995.

${ }^{19}$ Cooper, J.E., M.J. Desforges, P.R. Emmett, and J.R. Wright, "Advances in the Analysis of Flight Flutter Test Data," AGARD-CP-566, Nov. 1995.

${ }^{20}$ Liu, Ketao, Robert N. Jacques, and David W. Miller, "Frequency Domain Structural System Identification by Observability Range Space Extraction," American Control Conference Proceeding, June 1994.

${ }^{21}$ McKelvey, Tomas, Hüseyin Akçay, and Lennart Ljung, "Subspace-Based Multivariable System Identification from Frequency Response Data," IEEE Transactions on Automatic Control, vol. 41, no. 7, July 1996.

${ }^{22}$ Bendat, Julius S. and Allan G. Piersol, Engineering Applications of Correlation and Spectral Analysis, John Wiley \& Sons, Inc., 1980.

${ }^{23}$ Cadzow, James A., "Spectral Estimation: An Overdetermined Rational Model Equation Approach," Proceedings of the IEEE, vol. 70, no. 9, Sept. 1982.

${ }^{24}$ Cadzow, James A. and Otis M. Solomon, Jr., "Algebraic Approach to System Identification," IEEE Transactions on ASSP, vol. 34, no. 3, June 1986.

${ }^{25}$ Freudinger, Lawrence C. and Richard V. Field, Jr., "Null Space Pole Estimation with Error Bounds," $12^{\text {th }}$ International Modal Analysis Conference, Feb. 1994.

${ }^{26}$ Van der Auweraer, H. and P. Guillaume, A Maximum Likelihood Parameter Estimation Technique to Analyse Multiple Input/Multiple Output Flutter Test Data, AGARD-CP-566, Nov. 1995.

${ }^{27}$ Ljung, Lennart, System Identification: Theory for the User, Prentice-Hall, 1987.

${ }^{28}$ Pintelon, R., P. Guillaume, Y. Rolain, J. Schoukens, and $H$. Van hamme, "Parametric Identification of Transfer Functions in the Frequency Domain-A Survey," IEEE Transactions on Automatic Control, vol. 39, no. 11, Nov. 1994.

${ }^{29}$ Spanos, John T., "Algorithms for $l_{2}$ and $l_{\infty}$ Transfer Function Curve Fitting," AIAA-91-2807-CP, 1991. 
${ }^{30}$ Hakvoort, Richard G. and Paul M.J. Van Den Hof, "Frequency Domain Curve Fitting With Maximum Amplitude Criterion and Guaranteed Stability," International J. of Control, vol. 60, no. 5, 1994.

${ }^{31}$ Pfeffer, Lawrence E., "The RPM Toolbox: A System for Fitting Linear Models to Frequency Response Data," 1993 Matlab Conference, Oct. 1993.

${ }^{32}$ Pinkelman, J.K., S.M. Batill, and M.W. Kehoe, "An Investigation of the Total Least-Squares Criteria in Time Domain Based, Parameter Identification for Flight Flutter Testing," AIAA-95-1247, $36^{\text {th }}$ AIAA Structures, Structural Dynamics and Materials Conference, Apr. 1995.

${ }^{33}$ Rolain, Y., R. Pintelon, K.Q. Xu, and H. Vold, "On the Use of Orthogonal Polynomials in High Order Frequency Domain System Identification and its Application to Modal Parameter Estimation," 33rd Proceedings of Conference on Decision and Control, Lake Buena Vista, Florida, Dec. 1994.

${ }^{34}$ Rolain, Y., R. Pintelon, K.Q. Xu, and H. Vold, "Best Conditioned Parametric Identification of Transfer Function Models in the Frequency Domain," IEEE Transactions on Automatic Control, vol. 40, no. 11, Nov. 1995.

${ }^{35}$ Rosen, J. Ben, Haesun Park, and John Glick, "Total Least Norm Formulation and Solution for Structured Problems," SIAM J. of Matrix Analysis Applications, vol. 17, no. 1, Jan. 1996.

${ }^{36}$ Mäkilä, P.M., J.R. Partington, and T.K. Gustafsson, "Worst-Case Control-Relevant Identification," Automatica, vol. 31, no. 12, Dec. 1995.

${ }^{37} \mathrm{Gu}$, Guoxiang and Pramod P. Khargonekar, "Linear and Nonlinear Algorithms for Identification in $H_{\infty}$ with Error Bounds," IEEE Transactions of Automatic Control, AC-37, pp. 953-963.

${ }^{38}$ Gustaffson, T.K. and P.M. Mäkilä, "Modeling of Uncertain Systems via Linear Programming," Automatica, vol. 32, no. 3, Mar. 1996.

${ }^{39}$ VanOverschee, Peter and Bart DeMoor, Subspace Identification for Linear Systems: TheoryImplementation-Applications, Kluwer Academic Publishers, May 1996.

${ }^{40}$ Viberg, Mats, "Subspace-Based Methods for the Identification of Linear Time-Invariant Systems," Automatica, vol. 31, no. 12, Dec. 1995.
${ }^{41}$ Horta, Lucas G. and Jer-Nan Juang, "Frequency Domain System Identification Methods: Matrix Fraction Description Approach," AIAA-93-3839-CP.

${ }^{42}$ Juang, Jer-Nan, Lucas G. Horta, and Minh Phan, System/Observer/Controller Identification Toolbox, NASA TM-107566, Feb. 1992.

${ }^{43}$ Liu, Ketao and Robert E. Shelton, $Q$-Markov Cover Identification and Integrated MCA-OVC Controller Design for Flexible Structures, Ph.D. Thesis, Purdue University, Dec. 1991.

${ }^{44}$ Bayard, David S., "An Algorithm for State-Space Frequency Domain Identification Without Windowing Distortions," IEEE Transactions on Automatic Control, vol. 39, no. 9, Sept. 1994.

${ }^{45}$ Mehra, Raman K., Roberto G. Waissman, and Shahjahan Mahmood, Aircraft On-Line Flutter Parameter Identification: Vols. 1\&2, Final Report and User's Guide, Scientific Systems Company Inc., May 1993.

${ }^{46}$ Liu, Ketao and David W. Miller, "Structural System Identification: A Study of Different Algorithms," AIAA94-3622-CP.

${ }^{47}$ Miller, David W., Javier de Luis, Gregory Stover, Jonathan P. How, Ketao Liu, Simon C.O. Grocott, Mark E. Cambell, Roger Glaese, Edward F. Crawley, "The Middeck Active Control (MACE): Using Space for Technology Research and Development," American Control Conference Proceedings, Seattle, Washington, June 21-23, 1995.

${ }^{48}$ Liu, Ketao and David W. Miller, "Time Domain State Space Identification for Structural System Controls," $12^{\text {th }}$ International Modal Analysis Conference, Feb. 1994.

${ }^{49}$ Nikias, Chrysostomos L. and Athina P. Petropulu, Higher-Order Spectra Analysis, Prentice-Hall, 1993.

${ }^{50}$ Le Dzu, K., "Multiscale System Identification and Estimation," SPIE Intl. Symp., Conf. 2563, Advanced Signal Processing Algorithms, July 1995.

${ }^{51}$ Misiti, Michael, Yves Misiti, Georges Oppenheim, and Jean-Michel Poggi, Wavelet Toolbox User's Guide, The MathWorks, Inc., 1996.

${ }^{52}$ Smith, Roy S. and Mohammed Dahleh (eds.), The Modeling of Uncertainty in Control Systems, SpringerVerlag, 1994. 
${ }^{53}$ Lind, Rick and Marty Brenner, "Worst-Case Flutter Margins from F/A-18 Aircraft Aeroelastic Data," $38^{\text {th }}$ AIAA Structures, Structural Dynamics and Materials Conference, AIAA-97-1266, Apr. 1997.

${ }^{54}$ Lind, Rick and Martin J. Brenner, "Robust Stability Estimation of Aeroelastic Systems using Flight Derived Uncertainty Models," accepted by AIAA J. of Guidance, Control and Dynamics, March 1997.
${ }^{55}$ Poolla, Kameshwar, Pramod Khargonekar, Ashok Tikku, James Krause, and Krishan Nagpal, "A TimeDomain Approach to Model Validation," IEEE Transactions on Automatic Control, vol. 39, no. 5, May 1994.

${ }^{56}$ Gupta, K.K., M.J. Brenner, and L.S. Voelker, Development of an Integrated Aeroservoelastic Analysis Program and Correlation with Test Data, NASA TP-3120, May 1991. 
Public reporting burden for this collection of information is estimated to average 1 hour per response, including the time for reviewing instructions, searching existing data sources, gathering and maintaining the data needed, and completing and reviewing the collection of information. Send comments regarding this burden estimate or any other aspect of this collection of information, including suggestions for reducing this burden, to Washington Headquarters Services, Directorate for Information Operations and Reports, 1215 Jefferson Davis Highway, Suite 1204 , Arlington, including suggestions for reducing this burden, to Washington Headquarters Services, Directorate for intormation Operations and A
VA 22202-4302, and to the Office of Management and Budget, Paperwork Reduction Project (0704-0188), Washington, DC 20503.

\begin{tabular}{|l|r}
\hline 1. AGENCY USE ONLY (Leave blank) & 2. REPORT DATE \\
April 1997
\end{tabular}

REPORT TYPE AND DATES COVERED

Technical Memorandum

4. TITLE AND SUBTITLE

Overview of Recent Flight Flutter Testing Research at NASA Dryden

6. AUTHOR(S)

WU 522-32-34

Martin J. Brenner, Richard C. Lind, and David F. Voracek

7. PERFORMING ORGANIZATION NAME(S) AND ADDRESS(ES)

8. PERFORMING ORGANIZATION

REPORT NUMBER

NASA Dryden Flight Research Center

P.O. Box 273

H-2165

Edwards, California 93523-0273

10. SPONSORING/MONITORING

9. SPONSORING/MONITORING AGENCY NAME(S) AND ADDRESS(ES)

AGENCY REPORT NUMBER

National Aeronautics and Space Administration

Washington, DC 20546-0001

NASA TM-4792

\section{SUPPLEMENTARY NOTES}

Presented as AIAA 97-1023 at the 38th AIAA/ASME/ASCE/AHS/ASC Structures, Structural Dynamics, and Materials Conference and Exhibit, Kissimmee, Florida, April 7-10, 1997.

12a. DISTRIBUTION/AVAILABILITY STATEMENT

12b. DISTRIBUTION CODE

Unclassified-Unlimited

Subject Category 05

13. ABSTRACT (Maximum 200 words)

In response to the concerns of the aeroelastic community, NASA Dryden Flight Research Center, Edwards, California, is conducting research into improving the flight flutter (including aeroservoelasticity) test process with more accurate and automated techniques for stability boundary prediction. The important elements of this effort so far include the following: 1) excitation mechanisms for enhanced vibration data to reduce uncertainty levels in stability estimates; 2) investigation of a variety of frequency, time, and wavelet analysis techniques for signal processing, stability estimation, and nonlinear identification; and 3) robust flutter boundary prediction to substantially reduce the test matrix for flutter clearance. These are critical research topics addressing the concerns of a recent AGARD Specialists' Meeting on Advanced Aeroservoelastic Testing and Data Analysis. This paper addresses these items using flight test data from the F/A-18 Systems Research Aircraft and the F/A-18 High Alpha Research Vehicle.

\section{SUBJECT TEAMS}

Aeroelasticity, Aeroservoelasticity, Flutter, Model validation, Robust stability, Stability prediction, Structural dynamics, System identification, Wavelet analysis

17. SECURITY CLASSIFICATION OF REPORT

Unclassified OF THIS PAGE

Unclassified
18. SECURITY CLASSIFICATION
19. SECURITY CLASSIFICATION OF ABSTRACT

Unclassified
15. NUMBER OF PAGES

31

16. PRICE CODE

$\mathrm{AO} 3$

20. LIMITATION OF ABSTRACT

Unlimited 